\title{
Análisis morfométrico y morfotectónico de dos cuencas fluviales intermontanas colineales y opuestas de la Precordillera, Andes Centrales de Argentina
}

\author{
Morphometric and morphotectonic analysis of two collinear and opposite intermountain river \\ basins in the Precordillera, Central Andes of Argentina
}

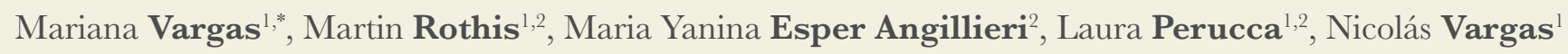

Gabinete de Neotectónica y Geomorfología. INGEO. Facultad de Ciencias Exactas, Físicas y Naturales. Universidad Nacional de San Juan, 5402, San Juan, Argentina.

${ }^{2}$ CIGEOBIO-UNSJ. Consejo Nacional de Investigaciones Científicas y Tecnológicas (CONICET), Av. Ignacio de La Roza y Meglioli s/n, 5400, San Juan, Argentina.

* Autor para correspondencia: (M. Vargas) marivargasperucca@gmail.com

\section{RESUMEN}

Las cuencas fluviales Gualilán-La Cantera se localizan en el ámbito de Precordillera Central, Andes centro-occidentales de Argentina. El drenaje regiona en esta depresión tectónica está controlado por el sistema de corrimientos que elevan la sierra de La Invernada por el oeste y por las fallas con actividad tectónica cuaternaria que constituyen el sistema de cabalgamiento La Cantera en su porción central y oriental. Ambas cuencas, colineales, opuestas, divergentes y con forma elongada en dirección N-S, se encuentran separadas por una suave divisora de aguas o portezuelo, sugiriendo que en el pasado constituyeron un mismo valle intermontano en el ámbito de Precordillera. El objetivo de este estudio es la caracterización morfométrica y morfotectónica de estas cuencas, complementada con un análisis de los procesos de captura fluvial. La cuenca del río Gualilán indicaría baja actividad tectónica cuaternaria de las estructuras que la limitan, mientras que las del río La Cantera poseen evidencia de mayor actividad tectónica cuaternaria. La pendiente media obtenida para la cuenca del río La Cantera es más elevada que la del río Gualilán. Además, el perfil de río Gualilán muestra knickpoints principalmente en su tramo superior. En cambio, el río La Cantera, ademá de mostrar knickpoints también en su tramo superior posee los mayores quiebres de pendiente en su tramo inferior. El sistema de Falla La Cantera (en adelante SFLC) contribuiría a generar estas variaciones en la pendiente a lo largo de ambos ríos, producto del movimiento de esta estructura con actividad pleistocena tardía-holocena y probablemente histórica. También se identificó una falla inversa con componente horizontal y rumbo E-O, coincidente con la cabecera de ambos ríos principales N-S, que influiría en la dinámica de ambos colectores principales. El elevado gradiente del cauce principal N-S y el fuerte desnivel entre la cabecera y desembocadura del río La Cantera respecto del río Gualilán, son factores que favorecen directamente la mayor erosión observada en el primero en relación al segundo. Esta erosión es remontante y se ve además favorecida por desarrollarse en un ambiente de rocas fácilmente degradables (areniscas, limolitas y conglomerados del Neógeno) Se espera que la evolución del río La Cantera hacia el norte culminará en un futuro en un proceso de captura de la cuenca endorreica del río Gualilán y el desvío de sus caudales hacia el captor (hacia el sur), con la desembocadura en el río San Juan, que es el nivel de base de la región. Este proceso parece ser frecuente en numerosos valles tectónicos longitudinales de la Precordillera de San Juan, cuya causa de rejuvenecimiento es considerada en este trabajo como dinámica (tectónica).

Palabras clave: Guenca fluvial, Gaptura fluvial, Neotectónica, Precordillera.

\section{ABSTRACT}

The Gualilan and La Cantera river basins are located in the Central Precordillera of the central-western Andean ranges of Argentina. Both river basins lie in a $\mathcal{N}-S$ tectonic depression. The regional drainage in the depression is controlled by two thrust-fault systems. To the west lies a system of thrusts associated with the Invernada mountain range. The eastern area is controlled by the La Cantera thrust system. Both basins, collinear, opposite and divergent, with an elongated shape in the $\mathcal{N}-S$ direction, are separated by a smooth water divide or "portezuelo." suggesting that in the past they comprised a single intermountain valley. The objective of this study is to make a morphometric and morphotectonic characterization of these river basins, complemented with an analysis of a stream piracy process. From this analysis, the Gualilan river basin suggests a low tectonic activity for the structures that cross the basin, while those of the La Cantera River have clear evidence of Quaternary tectonic activity. The average slope of the La Cantera river basin is steeper than that of the Gualilan river basin. Morover, the Gualilán longitudinal river profile shows several knickpoints, mainly in its upper section, while the La Cantera longitudinal river profile also shows knickpoints in its upper section but has the main slope breaks in its lower section. The La Cantera fault system would has contributed to generate these variations in the slope along both rivers, product of the late Pleistocene to Holocene and probably historical activity. This paper also describes a reverse fault with horizontal displacement trending $E-W$, coincident with the headwaters of both $\mathcal{N}-S$ rivers, which would also influence the dynamics of these basins. The high gradient of the main channel and the drop in elevation between the headwaters and the outlet of the La Cantera River with respect to the Gualilán River are factors that directly favor upstream erosion. Easily eroded rocks (sandstones, siltstones, and conglomerates of the Neogene) also favor the headward erosion. Erosion would culminate in a future process of piracy of the endorheic basin of the Gualitan River, and the deviation of its flows towards the captor (La Cantera River), down to the mouth of the San Juan River, which is the base level of the region. These capture processes seems to be frequent in many of the longitudinal tectonic valleys of the Precordillera, whose cause of rejuvenation is considered in this work as dynamic (tectonic).

Keywords: River basin, Stream piracy, Neotectonics, Precordillera. 


\section{Introducción}

La mayoría de los rasgos fisiográficos del área de la Precordillera de San Juan se encuentran fuertemente controlados por la estructuración miopliocena resultante de la orogenia andina. Se trata de cordones montañosos de rumbo N-S elevados por fallas del mismo rumbo que separan pequeñas cuencas intermontanas del tipo piggyback (Jordan et al., 1993). Estos valles son surcados por ríos de rumbo N-S que corren a lo largo de los ejes de las depresiones, denominados por Suriano y Limarino (2009) como sistemas río colector-conoide. Este término es utilizado para identificar a los depósitos resultantes de pequeños cursos fluviales que drenan longitudinalmente los valles intermontanos y forman prominentes conoides al alcanzar los sistemas de transferencia que drenan transversalmente el sistema de piedemonte (en este caso el río San Juan) o cuencas cerradas (endorreicas) como la Pampa de Gualilán. Estos sistemas colector-conoide se encuentran fuertemente controlados por las estructuras activas que atraviesan o limitan las depresiones que los mismos cruzan.

Por otro lado, el proceso de captura o decapitación de una cuenca fluvial se refiere a la apropiación del área de captación drenada por otro río sin mantener la misma dirección de drenaje y / o sin la presencia de codos del río (Bishop, 1995). Numerosos estudios han reconocido la influencia de la actividad tectónica cuaternaria y la captura de ríos, actuando juntos o individualmente, en la reorganización del drenaje en distintas regiones del mundo (Calvache y Viseras, 1997; Antón et al., 2014, entre otros). Los antecedentes referidos al análisis morfométrico y morfotectónico de cuencas fluviales que circulan por el eje de valles limitados por estructuras con actividad tectónica cuaternaria, son muy escasos en el centro-oeste de los Andes Centrales de Argentina. Lo mismo sucede con las investigaciones referidas a procesos de captura en cuencas de drenaje intermontanas colineales y opuestas. Es posible mencionar el trabajo de Vargas (2017) en el área de estudio y el de Perucca et al. (2018) en la región oriental de la provincia de San Juan, en el ámbito de sierras Pampeanas Occidentales. Sin embargo, en la región precordillerana sí existen numerosas investigaciones referidas a estudios neotectónicos y morfotectónicos de detalle asociadas a estructuras activas, en particular al SFLC (Bastías, 1986; Mingorance, 1998; Millán y Perucca, 2011; Perucca et al., 2014a, 2014b y 2015). Perucca et al. (2014a, 2014 b y 2015) describieron al SFLC como una de las principales estructuras activas en el ámbito de la Precordillera Central de San Juan, centro-oeste de Argentina (Figura 1a, 1b y 1c). Este sistema de falla ha modificado y controlado el paisaje del valle de los ríos La Cantera y Gualilán, generando escarpes a favor y en contra de la pendiente y anomalías en la red de drenaje, entre otros rasgos destacados.

La orientación promedio de las distintas secciones de falla del sistema es de $\mathrm{N} 20^{\circ} \mathrm{E}$ y las estructuras buzan al oeste entre $10^{\circ}$ y $30^{\circ}$ en el tramo norte, aproximadamente $40^{\circ} \mathrm{O}$ en el tramo central y hasta $60^{\circ} \mathrm{O}$ en el extremo sur, con un buzamiento promedio de $30^{\circ} \mathrm{O}$ para todo el sistema (Figura la y 1b). Se trata de cabalgamientos que deforman y desplazan todos los niveles de abanicos aluviales desde el Pleistoceno medio al Holoceno tardío en el piedemonte oriental de la sierra de La Invernada y occidental de la sierra de La Cantera y están definidos por una serie de geoformas típicas de fallamiento activo de carácter compresivo. Se destacan escarpes de falla a favor y en contra de la pendiente, simples y compuestos, escarpes flexurales, terrazas fluviales escalonadas, lagunas de falla, fuentes alineadas, redes en rastrillo, cauces desplazados, obturados, colgados y con diferentes grados de incisión (Perucca et al. 2014a y 2014b). Presentan, así, evidencias sobre la reactivación cuaternaria tardía del SFLC, un cabalgamiento de vergencia oriental, enlazando los episodios tectónicos con las modificaciones del paisaje. La presente investigación tuvo como objetivo principal la obtención de información morfológica, morfométrica y estructural sobre los cambios geomorfológicos en las cuencas intermontanas de los ríos La Cantera y Gualilán 

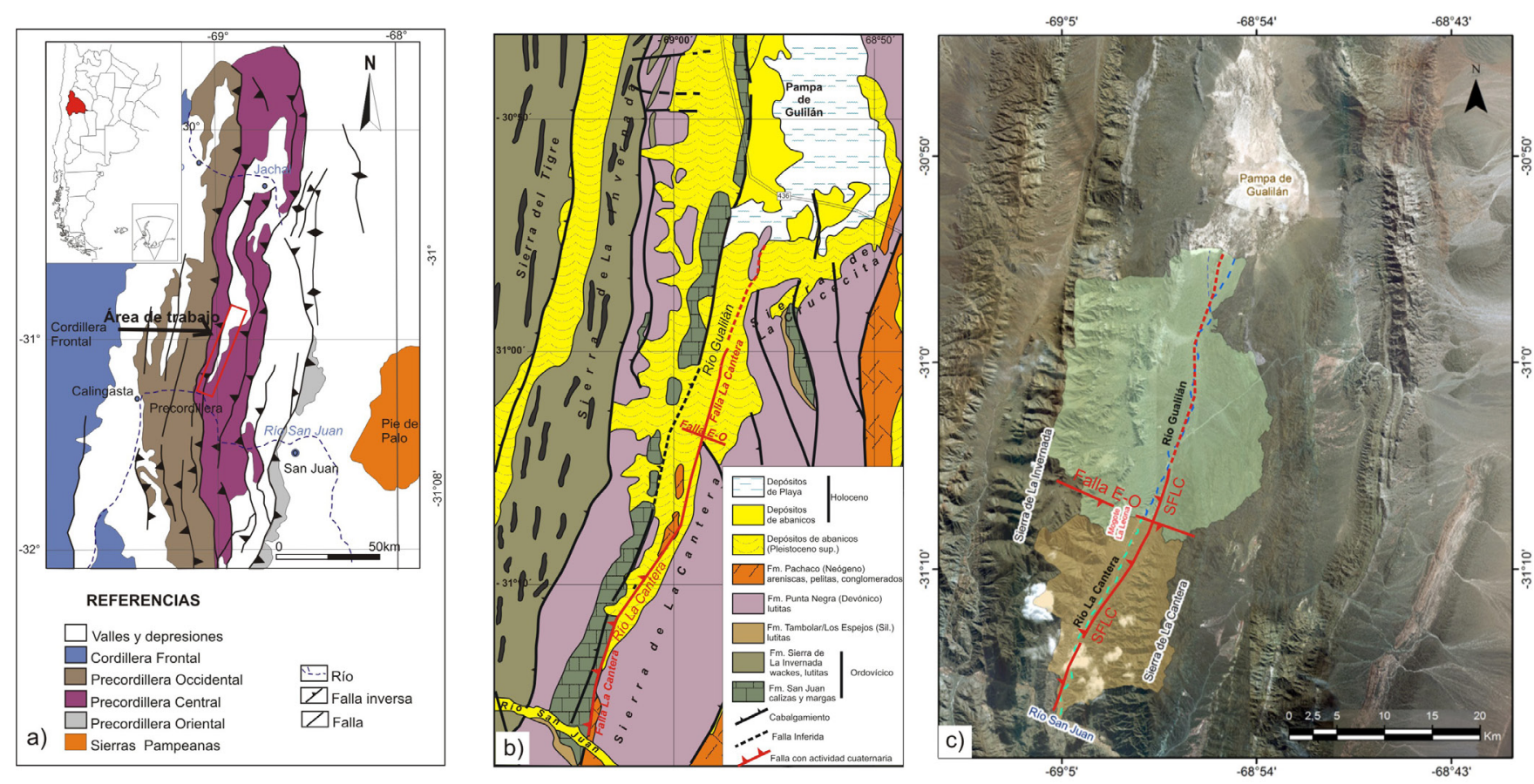

Figura 1 a) Ubicación del área de estudio en la provincia de San Juan, Argentina; b) Mapa geológico del sector y ubicación de los principales trazos de falla activos (Sistema de Falla La Cantera y falla E-O) a lo largo del valle intermontano Gualilán-La Cantera en el ámbito de Precordillera; c) Imagen satelital del área de estudio y ubicación de las cuencas de los ríos Gualilán-La Cantera y de las principales secciones de falla con evidencia de actividad tectónica pleistocena tardío-holocena.

(Figura 1c), con el fin de evaluar la influencia de la actividad tectónica cuaternaria (SFLC) y la capacidad del escurrimiento superficial para modificar o adaptarse a las deformaciones activas en el sector de la Precordillera de San Juan, ubicado al norte del río San Juan. De este modo, se intenta ampliar el conocimiento acerca de la estructuración de la región, a través de la evolución tectónica y geomorfológica de cuencas fluviales intermontanas.

\section{Ubicación del área de estudio}

El área de estudio se ubica en la región centro-sur de la provincia de San Juan, correspondiente al departamento Ullum, a aproximadamente 105 $\mathrm{km}$ al oeste de la ciudad capital (San Juan) entre los $30^{\circ} 55^{\prime}$ y $31^{\circ} 15^{\prime} \mathrm{S}$ y entre los $68^{\circ} 50^{\prime}$ y $69^{\circ} 10^{\prime}$ O (Figura 1b y 1c). El valle Gualilán-La Cantera se encuentra entre dos cordones montañosos que se alinean con dirección norte-sur, la sierra de La Invernada (3500 msnm) por el oeste y la sierra de La Cantera (3000 msnm) por el este. Este valle se extiende desde el Puesto de Pachaco sobre el río San Juan (1190 msnm) en el sur, hasta la Pampa de Gualilán (1620 msnm) en el norte (Figura 1c).

Este valle tectónico se encuentra además compartimentado en dos cuencas fluviales de rumbo N-S, colineales y opuestas. La cuenca del río Gualilán, cuyo río principal corre de sur a norte, y la del río La Cantera, que se dirige de norte a sur. En términos generales, el clima en la región es desértico, con escasas precipitaciones durante los meses de verano, con temperaturas cercanas a los $35^{\circ} \mathrm{C}$ en verano y en invierno en el orden de los 16 ${ }^{\circ} \mathrm{C}$, con presencia de heladas con temperaturas de $-8{ }^{\circ} \mathrm{C}$ o inferiores. Los vientos predominantes son del cuadrante sur-sureste. Es de destacar el viento seco local denominado Zonda, frecuente entre el otoño y la primavera (Poblete y Minetti, 1989). 


\section{Marco Tectónico y Geológico}

La provincia geológica Precordillera es un orógeno paleozoico que muestra diferentes estilos estructurales, los cuales fueron agrupados por Ortiz y Zambrano (1981) en Precordillera Occidental, Central y Oriental. La Precordillera Central está constituida por cordones montañosos de orientación meridional que se extienden a lo largo de toda la provincia de San Juan. Corresponde a una faja plegada y corrida, con un estilo estructural tipo piel delgada (thin-skinned), con pliegues de vergencia oriental (Rolleri, 1969; Ramos, 1999).

Está constituida por al menos cuatro y hasta seis corrimientos principales con su nivel de despegue en la secuencia cambro-ordovícica (Allmendinger et al., 1990), corrimientos fuera de secuencia como la falla La Cantera (Perucca et al., 2015) y estructuras de interferencia resultantes de la interacción con la estructuración de la Precordillera Oriental constituida por fallas de alto ángulo, de vergencia occidental (Zapata y Allmendinger, 1996). Allmendinger et al. (1990) y Von Gosen (1992) destacaron, en la estructura de Precordillera Central, el continuo incremento del buzamiento de los cabalgamientos desde $30^{\circ}$ en su sector frontal, hasta vertical y/o volcado (retrocabalgamientos) en el sector más occidental (Figura la y 1b).

La estratigrafía en la Precordillera Central está representada por rocas de edad cambro-ordovícica (calizas y dolomías), siluro-devónica (olistolitos, areniscas y lutitas), carbonífera (areniscas y lutitas) y neógena (conglomerados, areniscas y arcilitas). El Cuaternario está representado principalmente por depósitos aluviales y coluviales (Figura 1b).

Las rocas del Neógeno que afloran en el área se disponen en discordancia angular sobre rocas del Paleozoico, y también han sido involucradas en los plegamientos y cabalgamientos de la Precordillera. La mayor parte de las estructuras andinas han sido consideradas reactivaciones de estructuras antiguas originadas durante el Carbonífero a Pérmico (Alonso et al., 2005). La deformación andina es considerada como Miocena a reciente, con el avance del frente orogénico desde el oeste hacia el este (Jordan et al., 1993). El Cuaternario está representado por los depósitos que conforman las geoformas pedemontanas, principalmente abanicos aluviales, conos aluviales y llanuras aluviales (Perucca et al. 2014a y 2015), tanto de la sierra de la Invernada por el oeste, como de la sierra de la Cantera por el este. Estos depósitos están constituidos por clastos de grauvacas, calizas, areniscas y escasas rocas plutónicas.

\subsection{MARGO NEOTECTÓNICO}

El Sistema de Falla La Cantera (SFLC) es una de las principales estructuras activas en el ámbito de la Precordillera Central de San Juan, la cual se extiende por $47 \mathrm{~km}$ en dirección Norte - Sur a lo largo del valle que separa las sierras de La Cantera y La Invernada, al norte del río San Juan. Este sistema de fallamiento ha modificado el paisaje del valle formado por las cuencas de los ríos $\mathrm{La}$ Cantera y Gualilán, generando escarpas de falla a lo largo de todo su trazado y diversas anomalías en la red de drenaje (Millán y Perucca, 2011 ; Perucca et al., 2014 y 2015).

Perucca et al. (2015) efectuaron estudios paleosísmicos en el SFLC y sugirieron al menos cuatro terremotos durante los últimos 11000 años en coincidencia con los resultados obtenidos por Mingorance (1998). La deformación observada en una terraza aluvial con una edad 11962 a 11615 Cal años BP, en el segmento central del sistema de falla, indicaría al menos dos eventos sísmicos. En las otras dos trincheras ubicadas en la porción norte y central del sistema Perucca et al. (2015) señalaron que la falla afecta un suelo cuya edad es de $4580 \pm 50$ Cal años BP y 4865 a 4830 Cal años BP, respectivamente. Finalmente, en el extremo norte, un depósito afectado por la falla arrojó una edad $2600 \pm 30 \mathrm{Cal}$ años BP, indicando que la falla estuvo activa durante el Holoceno tardío. Por otro lado, Mingorance (1998) señaló que el terremoto de 1924 (Ms = 6.0) se produjo en el tramo centro-norte del Sistema de Falla, cerca de la divisoria de aguas, creando un escarpe de $0.30 \mathrm{~cm}$. 
En el portezuelo que divide ambas cuencas fluviales se ubica una falla inversa de rumbo O-E que inclina $35^{\circ}$ a $40^{\circ}$ al sur y dispone rocas del Neógeno sobre depósitos aluviales cuaternarios, los cuales se encuentran fuertemente cementados (Figuras 1b y 1c; 2a y 2b). La falla no corta la superficie pero genera un suave escarpe flexural hacia el norte. Se han medido estrías con un pitch $20^{\circ}$ y dirección $130^{\circ}$, indicando una componente horizontal dextral. Esta estructura es claramente visible en imágenes satelitales ya que se aprecia un desplazamiento dextral del frente montañoso de la sierra de La Cantera (Figura 1b y 1c).

\section{Materiales y metodología}

La delimitación de las cuencas se realizó a partir de la interpretación de imágenes satelitales de alta resolución adquiridas a partir de Google Earth ${ }^{\mathrm{TM}}$, con la ayuda de modelos digitales de elevación con 30 m de resolución (ASTER GDEM V2) (NASA, 2011), basada en el concepto de línea divisoria de aguas. Las imágenes fueron georeferenciadas en coordenadas geográficas (WGS84) a través de tecnología SIG. Para la delimitación de las cuencas fluviales y su caracterización morfométrica, se utilizaron imágenes satelitales, cartas topográficas y hojas geológicas de escala regional y de detalle.

Además, las mismas cuencas fueron delimitadas automáticamente en ambiente SIG utilizando los algoritmos de dirección del flujo y acumulación de flujo. Las direcciones de flujo se calcularon usando el modelo de flujo de dirección ocho (D8), que determina el flujo de cada celda de la cuadrícula a una de sus ocho celdas adyacentes, en la dirección con una pendiente descendente más empinada. El método D8 fue introducido primeramente por O'Callaghan y Mark (1984). La acumulación de flujo, en su forma más simple, es el número de células de ladera que desembocan en cada celda. Este método se basa en la suposición de que el flujo subsuperficial sigue la topografía.

La determinación del orden de cuencas se basó en la metodología propuesta por Strahler (1964). Los parámetros morfométricos básicos obtenidos fueron: área $(\mathrm{A})$, perímetro $(\mathrm{P})$, longitud $(\mathrm{L})$, ancho $(\mathrm{W})$, orden $(\mathrm{Rn})$, altura máxima y mínima $(\mathrm{H}, \mathrm{h})$, y parámetros derivados coeficiente de compacidad (kc), relación de elongación $(\mathrm{Re})$, factor de forma $(\mathrm{Ff})$, densidad de drenaje (Dd), índice medio de potencia (Ip), entre otros.

La caracterización morfotectónica se realizó con base en los marcadores propuestos por Keller y Pinter (2002), Scheidegger (2004) y Bull (2007). El índice morfotectónico longitud-gradiente (SL) fue obtenido para cada cauce principal colector en las dos subcuencas (de rumbo N-S) y para el curso considerado desde su nacimiento hasta su nivel de base, empleando el método propuesto por Hack (1973), quien desarrolló un método para el análisis del perfil longitudinal de un río basado en la relación que existe entre la distribución de la pendiente y su longitud. Este índice está íntimamente relacionado con la capacidad de transporte del río, siendo constante cuando el perfil está en equilibrio. Para el análisis morfotectónico de las cuencas de drenaje, se efectuó la determinación y análisis de los siguientes índices: sinuosidad del frente montañoso (S) de la sierra de La Invernada, asimetría de las cuencas, índices de longitud-gradiente de los ríos, perfiles de equilibrio, perfiles de franja (swath profiles), pendiente media de las cuencas y pendiente de los ríos principales, entre otros. Sobre la base de este análisis se evaluó un futuro proceso de captura fluvial y el posible basculamiento tectónico del sector.

Los resultados conseguidos fueron sistematizados a través de mapas, cuadros y diagramas, mediante el uso de software específico tal como QGis, SAGA GIS y ArcGis. 


\section{Resultados}

\section{1. ÍNDICES MORFOMÉTRICOS Y MORFOTEGTÓNICOS}

De los diferentes análisis efectuados en ambas cuencas analizadas es posible señalar que el drenaje regional en la depresión del valle Gualilán - La Cantera tiene una orientación general N-S, y está controlado por el sistema de cabalgamientos que elevan la sierra de La Invernada al oeste y las fallas con actividad tectónica cuaternaria que constituyen el sistema de cabalgamiento La Cantera por el este (Figura 1b y 1c). De acuerdo con esta relación estructural, es interpretado como un valle de falla o longitudinal. También la estructura activa de rumbo O-E (Figura 2a y 2b) habría controlado principalmente la formación de un portezuelo que dividió este valle longitudinal en dos cuencas cuyos ríos colectores N-S son opuestos. Los tributarios de ambos sistemas colectores provienen de las sierras aledañas, sierra de La Invernada por el oeste (cuyas alturas superan los $3500 \mathrm{msnm}$ a lo largo de todo el cordón montañoso) mientras que por el este descienden desde la sierra de La Cantera (cuyas alturas alcanzan los $3000 \mathrm{msnm}$ ) (Figura 3a y 3b). Los ríos y arroyos temporarios provenientes de estos cordones montañosos drenan desde el mogote La Leona hacia el norte, por el río Gualilán a la pampa de Gualilán, que es una cuenca endorreica que constituye un nivel de base regional (Figura 4a). Hacia el sur del mogote La Leona, los arroyos provenientes tanto la sierra de La Invernada como de la sierra de La Cantera drenan hacia el sur por la quebrada de La Cantera hasta su nivel de base local que es el río San Juan (Figura 4b). Ambas cuencas, colineales y divergentes, de forma elongada en dirección N-S, se encuentran separadas por una suave divisora de aguas o portezuelo ubicado a $2182 \mathrm{msnm}$.

El río Gualilán posee algunas similitudes con los sistemas ríos colectores que drenan una cuenca del tipo cerrada descritos para éste y otros ríos de Precordillera por Suriano y Limarino (2009) y Suriano et al. (2015), es decir, un curso fluvial que drena longitudinalmente un valle intermontano hasta un sector de playa lake dominado por depósitos finos. Este sistema posee los tres elementos principales característicos: 1) cuenca de captación, 2) sistema colector y 3) conoide y bajo gradiente en toda su extensión. Los mismos presentan gradientes bajos tanto en la zona proximal como en la distal, ya que el gradiente del sistema río colector conoide es de $10^{\circ}$ a $15^{\circ}$ en las cabeceras, pero sólo $1^{\circ}$ a $5^{\circ}$ en el pie (Bilkra y Nemec, 1998). El río Gualilán posee una pendiente promedio de $1.8 \%$, con un máximo de $6-5 \%$ en sus cabeceras y del $1 \%$ en su desembocadura en la Pampa del mismo nombre.

Además, la cuenca del río Gualilán posee un diseño dendrítico (Figura 4a), se encuentra bien integrada, posee una longitud aproximada de 25 $\mathrm{km}$ y un azimut de $17^{\circ}$. Su ancho máximo es de $20 \mathrm{~km}$ y el mínimo $13 \mathrm{~km}$. Según la clasificación de Strahler (1964), es una cuenca de 6to orden. El río Gualilán posee un diseño monocanal, con meandros encajados en su tramo inicial, donde la pendiente es mayor, posiblemente debido al control tectónico ejercido por el Sistema de Falla La Cantera (SFLC), para finalizar en su curso inferior con un diseño multicanal trenzado y divergente cerca de su desembocadura, donde la pendiente es mínima. El colector principal o río Gualilán presenta un perfil longitudinal ligeramente cóncavo principalmente en el tramo superior y medio, con una suave convexidad en su parte inferior, hacia el NNE de la cuenca (Figura 5a). Muestra algunos knickpoints en el tramo superior de la cuenca, cerca del mogote La Leona. Por el contrario, el perfil longitudinal del río, considerando sus cabeceras en la sierra de La Invernada, es cóncavo, sugiriendo un perfil en equilibrio (Figura $5 b$ ).

Por otro lado, el río La Cantera constituiría, de acuerdo a Suriano et al. (2015), un sistema colector abierto que drena hacia un sistema de transferencia constituido por un gran río (en este caso el río San Juan), el cual a su vez drena la faja plegada y corrida y transfiere los sedimentos de esta cuenca piggyback hacia el antepaís. La pendiente promedio del río La Cantera es de $4.7 \%$, 


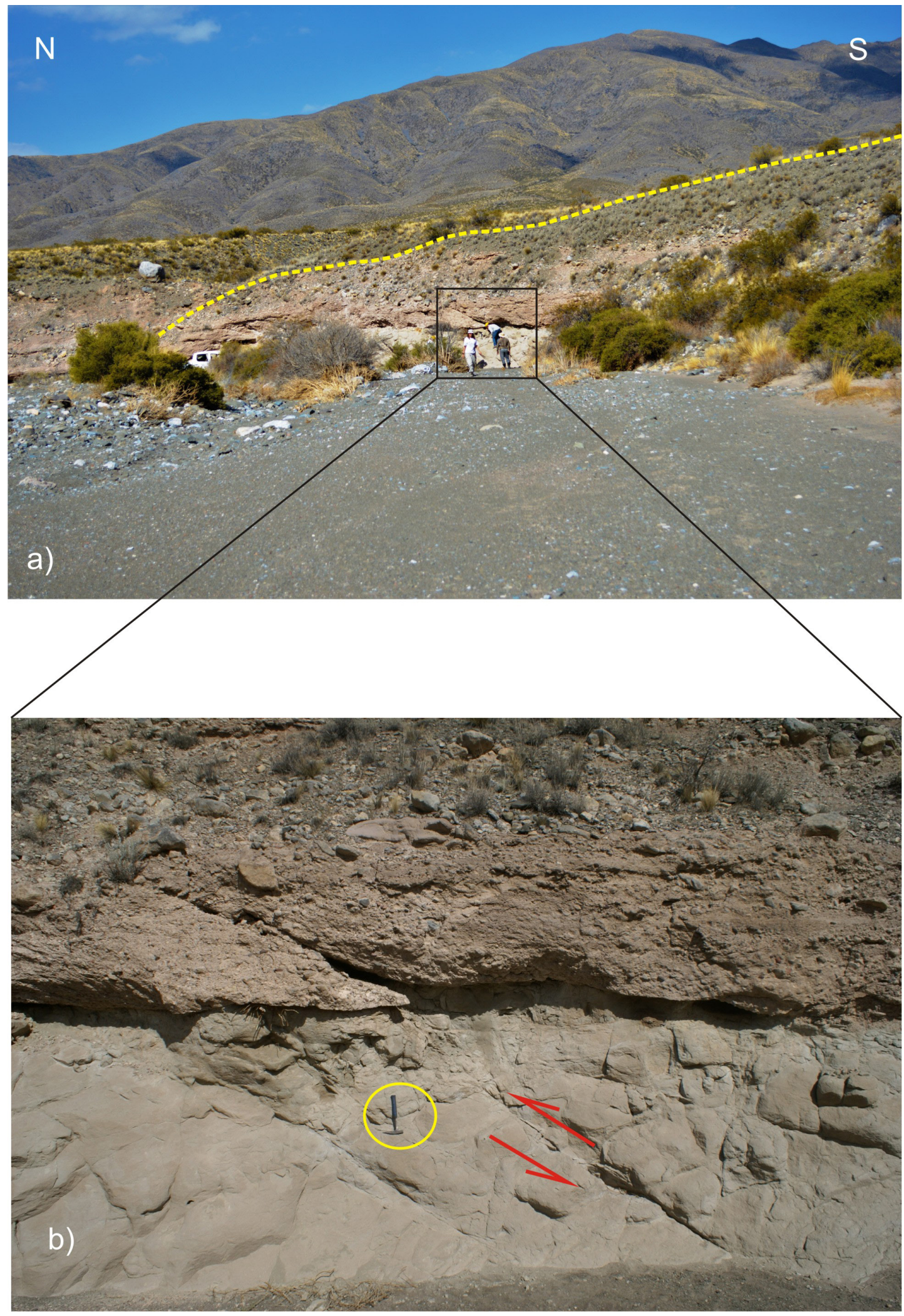

Figura 2 a) Exposición natural en el área del mogote La Leona (río Gualilán). Se aprecia una falla inversa que coloca rocas del Neógeno sobre depósitos aluviales cuaternarios fuertemente cementados. La falla forma un suave escarpe flexural con la cara libre hacia el norte; b) Detalle de la falla inversa. El círculo amarillo rodea un martillo a modo de escala. 
con una máxima de $9 \%$ en sus tramos tanto medio como distal. La cuenca del río La Cantera (Figura 4b) es de $4^{\text {to }}$ orden, está bien integrada y posee un diseño subdendrítico con cierto control estructural en los tributarios provenientes de la sierra de La Cantera y de la Invernada al interceptar el SFLC, formando un ángulo casi recto, tal como lo señalaron Millán y Perucca (2011). Su longitud aproximada es de $20 \mathrm{~km}$, con un azimut de $20^{\circ}$, ancho máximo de $11 \mathrm{~km}$ y mínimo de 3,5 $\mathrm{km}$ cerca de su desembocadura en el río San Juan.

$\mathrm{Al}$ contrario del río Gualilán, el perfil longitudinal del colector principal o río La Cantera es notoriamente convexo (Figura 5c), lo que de acuerdo con Whittaker et al. (2007) señalaría una tasa de levantamiento mayor que la capacidad de incisión del río. Los knickpoints se aprecian principalmente en el tramo superior e inferior del río colector, asociados a los trazos de falla activos del SFLC y la falla O-E. Al considerar la longitud del río desde sus cabeceras en la sierra de la Invernada, la curva es ligeramente cóncava, sugiriendo un estado de equilibrio. Prácticamente no se aprecian knickpoints en este sector y se relacionan principalmente con la salida del río del frente montañoso, ya que las litologías en el sector son similares (Figura 5d). En el valle se aprecia que el diseño del cauce principal es monocanal, ligeramente sinuoso en sus cabeceras y multicanal (moderado) en su tramo final, donde la red muestra un diseño divergente.

Desde el punto de vista geomorfológico, el valle del río Gualilán es ancho y poco incidido, con terrazas de acumulación (fill terraces) de escasos centímetros de altura (Figura 6a), a excepción de las terrazas de erosión (strath terraces), ubicadas en

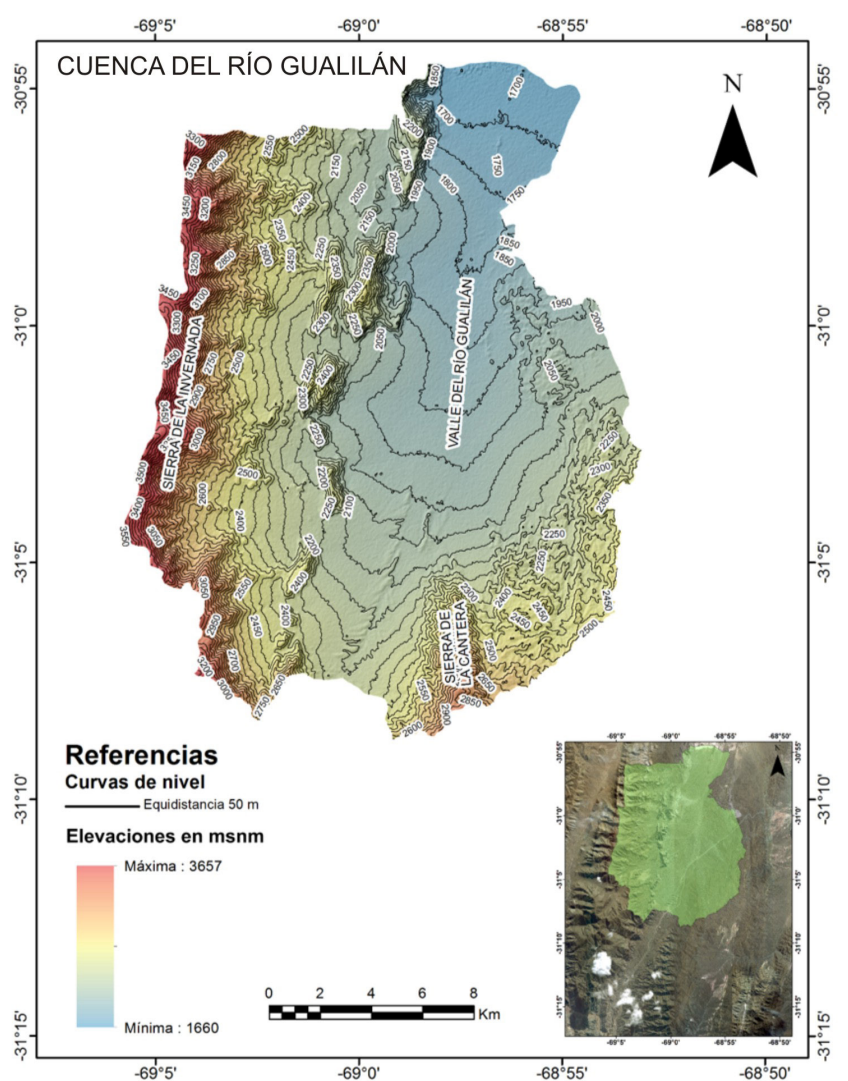

a)

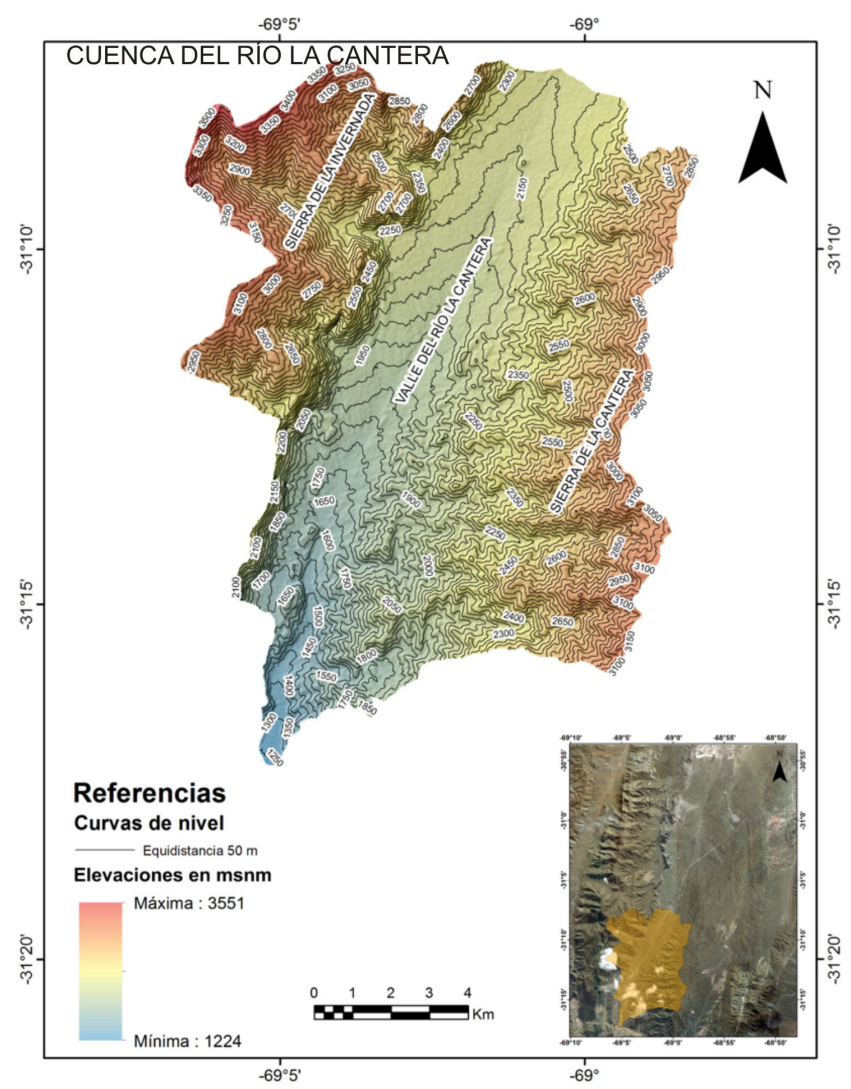

b)

Figura 3 Mapas topográficos en los que se muestran las curvas de nivel con las diferentes elevaciones en las cuencas hidrográficas a) del río Gualilán, b) del río La Cantera. Las máximas alturas (> $3500 \mathrm{msnm}$ ) se ubican en la sierra de La Invernada, al oeste de la depresión, producto de los cabalgamientos con vergencia al este que controlan el flanco oriental de dicha sierra. 

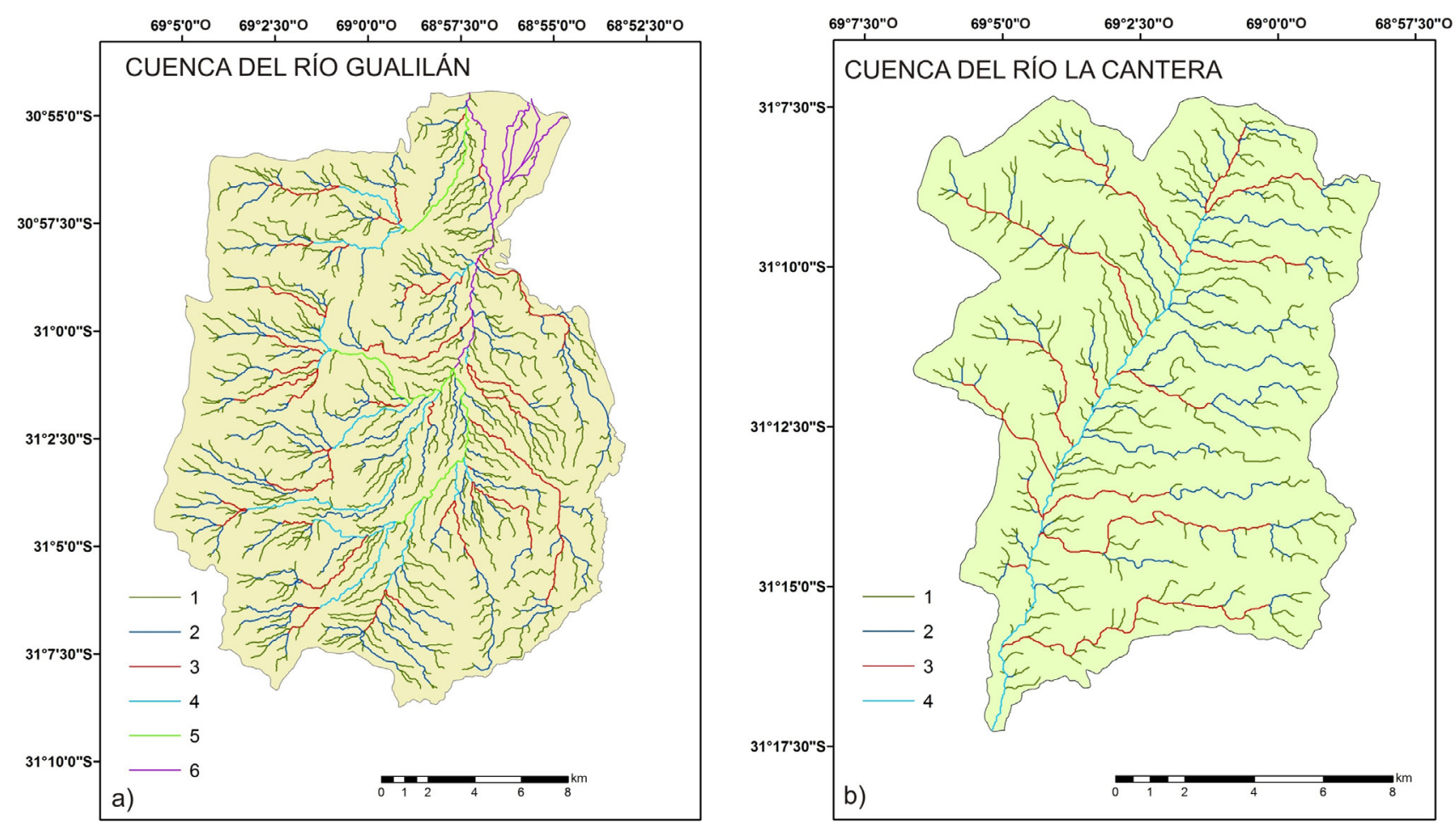

Figura 4 a) Cuenca del río Gualilán y número de orden, b) Cuenca del río La Cantera y número de orden.

su tramo superior [donde aflora el Neógeno unos $5 \mathrm{~m}$ (Figura 6b)], con una espesa cubierta aluvial, quienes en el sector del mogote La Leona se encuentran afectadas por una sección del sistema de falla La Cantera, de rumbo N-S y vergencia oriental y de la falla inversa de rumbo casi E-O (Figura 1c). Finalmente, el río Gualilán desemboca con un diseño en abanico divergente en la Pampa de Gualilán, una cuenca endorreica en la que predominan los depósitos finos (limos y arcillas), la cual es inundada efímeramente durante las lluvias torrenciales que ocurren en la región, constituyendo un nivel de base local (Figura 6c).

Por otro lado, en la cuenca del río La Cantera, predomina un diseño del tipo braided (Figura $6 \mathrm{~d})$, con desarrollo de dos terrazas de erosión (strath terraces) en ambas márgenes, labradas en rocas del Neógeno y cuyo cauce fluvial se vuelve cada vez más estrecho e incidido hacia el sur (Figura 5e), hasta su desembocadura al río San Juan. En el sector de la desembocadura, sobre la margen derecha del río La Cantera, y asociadas al levantamiento de los niveles calcáreos de la sierra de La Invernada por una sección del SFLG, se identificaron dos terrazas de erosión (strath terraces) del río N-S, las que fueron asignadas tentativamente al Pleistoceno tardío. En este sector, la falla coloca rocas del Neógeno por sobre los depósitos de la terraza aluvial más antigua. Topográficamente más bajas se ubican dos niveles de terrazas de acumulación (fill terraces) y el cauce actual del río. Sobre la margen izquierda se ubica una sola terraza de acumulación recostada en la sierra de La Cantera (Figura 6f).

Con respecto a los parámetros morfométricos de ambas cuencas (Tabla 1), la superficie (A) de la cuenca del río Gualilán puede ser clasificada según Villón (2002) como una cuenca grande (> $250 \mathrm{~km}^{2}$ ), mientras que la del río La Cantera es considerada una cuenca pequeña $\left(<250 \mathrm{~km}^{2}\right)$. La longitud (L) de la cuenca del río Gualilán es también mayor que la del río La Cantera.

La cuenca del río Gualilán posee un perímetro mayor que la del río La Cantera, mientras que el ancho medio (W) de la cuenca del río Gualilán es el doble que el del río La Cantera. 
Perfil longitudinal río Gualilán (Tramo N-S)

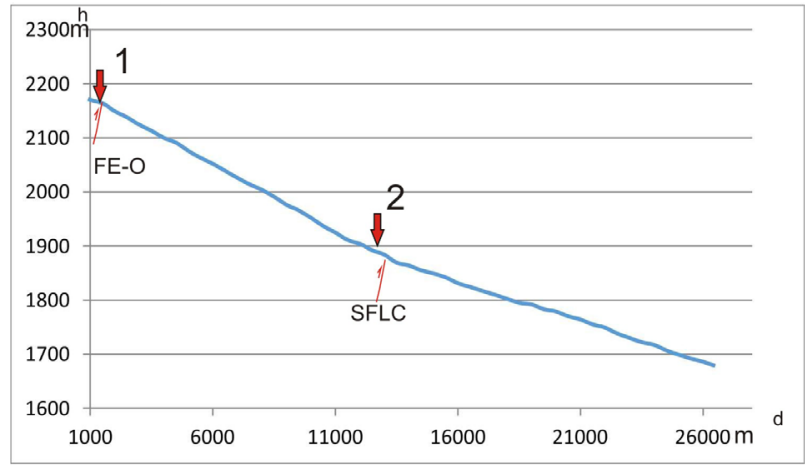

a)

Perfil longitudinal río La Cantera (Tramo N-S)

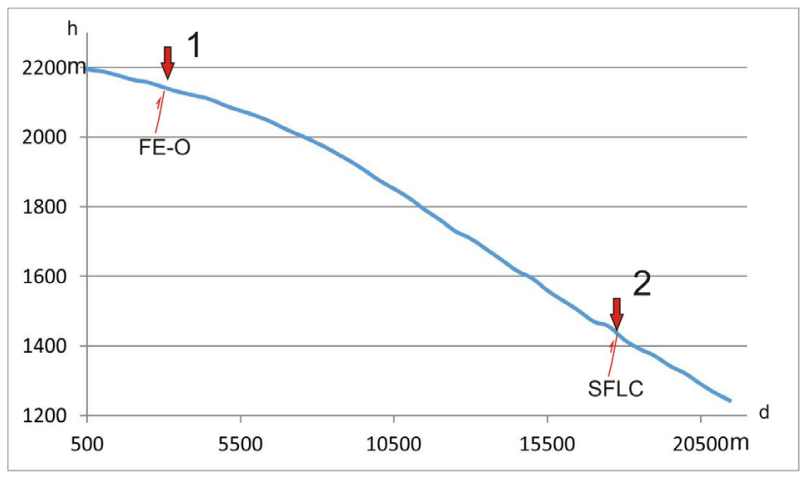

c)
Perfil longitudinal río Gualilán (Cabeceras sierra de La Invernada)

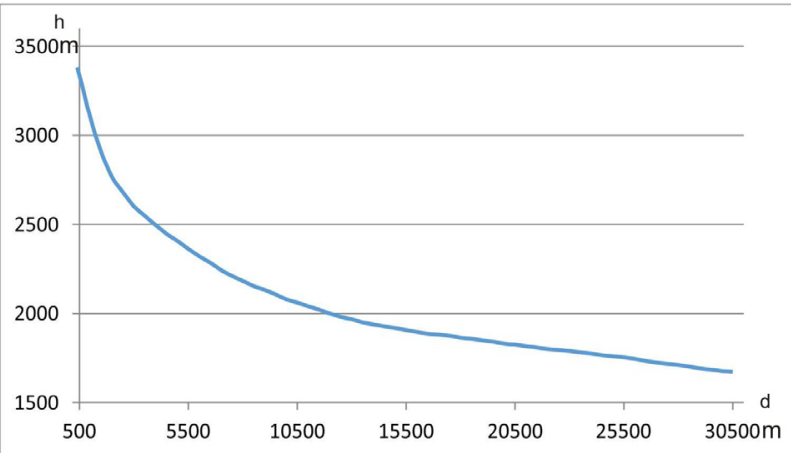

b)

Perfil longitudinal río La Cantera (Cabeceras sierra de La Invernada)

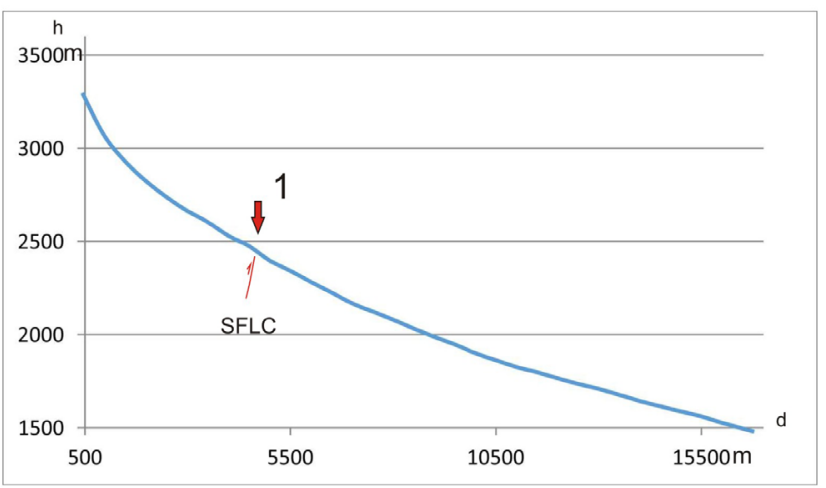

d)

Figura 5 a) Perfil longitudinal del río Gualilán en su tramo N-S, según el eje del valle. Se aprecia un río no equilibrado, las flechas indican knickpoints en su tramo superior (1) relacionado con la falla E-O y en su tramo medio (2), posiblemente relacionado con la traza no aflorante del SFLC; b) Perfil longitudinal cóncavo del río Gualilán desde su cabecera en la sierra de La Invernada hasta el nivel de base en la Pampa de Gualilán; c) Perfil longitudinal del río La Cantera en su tramo N-S paralelo al eje del valle. Las flechas indican los knickpoints en el tramo superior (1) relacionado a la falla E-O e inferior del río (2), en el sector en que la traza activa del SFLC lo cruza para elevar hacia el sur, el flanco oriental de la sierra de La Invernada; d) Perfil longitudinal del río La Cantera desde su cabecera en la sierra de La Invernada hasta el nivel de base en el río San Juan. Se aprecia un knickpoint (1) al cruzar el tributario de la margen derecha, la falla La Cantera que eleva la sierra.

El factor de forma $(\mathrm{Ff})$ es uno de los índices más utilizados para medir la forma de una cuenca (Horton, 1932). El valor obtenido para la cuenca del río Gualilán indica una cuenca ensanchada, mientras que el de la cuenca del río La Cantera corresponde a una cuenca más alargada (Tabla 1).

La Relación de elongación (Re) introducida por Schumm (1956) relaciona el diámetro del círculo asociado con la longitud de la cuenca. Los valores de Re inferiores a 1 implican formas alargadas, y cuanto menor sea Re más alargada será la forma de la cuenca. Para el caso de la cuenca del río Gualilán, la relación de elongación indica una cuenca menos alargada que la del río La Cantera (Tabla 1).

La pendiente media obtenida para la cuenca del río Gualilán es $12.4 \%$ (Figura 7a), con un río principal o colector cuya pendiente es del 1.8\% y una pendiente máxima de $6-5 \%$, cerca del mogote La Leona, donde predomina la incisión vertical, y una pendiente de menos del $1 \%$ en su desembocadura en la Pampa de Gualilán, donde predomina la depositación. La cuenca del río La Cantera posee una pendiente media mayor, con un valor de $20.55 \%$ (Figura $7 b$ ), lo que evidencia un terreno fuertemente accidentado, con el río 

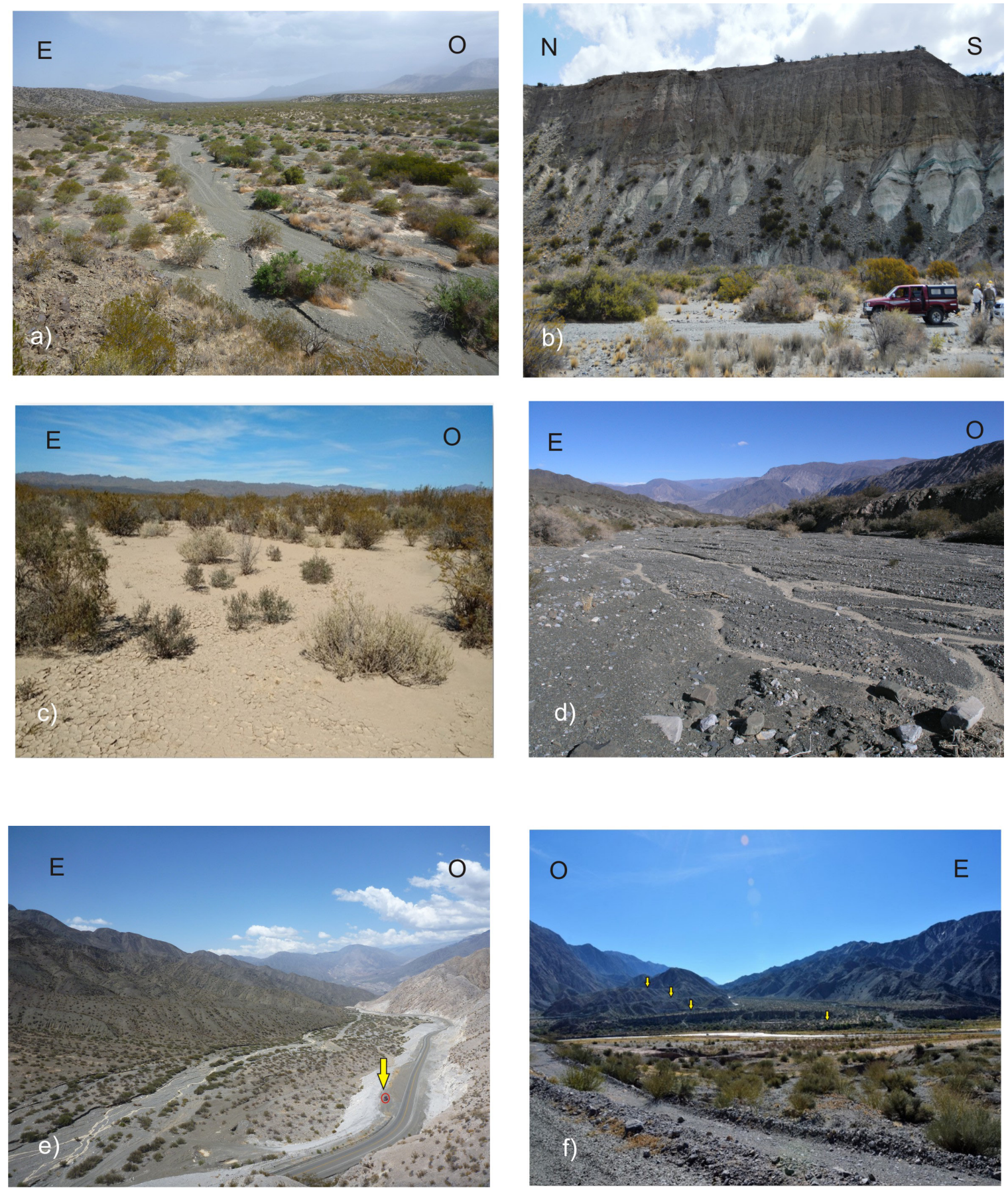

Figura 6 a) Vista hacia el sur del río Gualilán. Es posible apreciar la baja incisión del río en el sector, el fondo plano del mismo y la ausencia de terrazas fluviales de envergadura; b) Vista de una terraza de erosión generado en el flanco izquierdo del río Gualilán. Las rocas del Neógeno afloran además por la acción de una sección de falla del Sistema La Cantera, coincidente en este sector con el río. Por encima destacan los depósitos fluviales cuaternarios (el vehículo de la derecha se encuentra a modo de escala); c) Depósitos finos en la desembocadura del río Gualilán en la Pampa del mismo nombre. En ella se desarrolla abundante vegetación; d) Vista hacia el sur del tramo superior del río La Cantera, en la que se aprecia el fondo plano y diseño tipo braided del río; e) Vista hacia el sur del tramo inferior del río, en el que se aprecia la fuerte incisión del cauce y el estrechamiento del valle (la flecha señala un vehículo a modo de escala); f) Vista hacia el norte de la desembocadura del río La Cantera en el río San Juan. Se aprecian cuatro niveles de terrazas fuertemente incididas (indicadas por las flechas) en la margen occidental del río, las dos más elevadas y antiguas corresponden a terrazas de erosión (strath terraces) y las dos más bajas y posiblemente más modernas corresponden a terrazas de acumulación (fill terraces). En el margen izquierdo solamente se ubica un nivel de terraza de acumulación. 
Tabla 1.Parámetros morfométricos de las cuencas de los ríos Gualilán y La Cantera. Donde $\mathrm{A}=$ área, $\mathrm{P}=$ perímetro, $\mathrm{L}=\mathrm{longitud} \mathrm{de} \mathrm{la}$ Cuenca, $\mathrm{H}=$ altura máxima, $\mathrm{h}=$ altura miníma, $\mathrm{On}=$ orden de la cuenca; $\mathrm{Kc}=$ Índice de Compacidad, $\mathrm{Re}=$ relación de Elongación, $\mathrm{Ff}=$ factor de Forma, $\mathrm{S}=$ sinuosidad, $\mathrm{Dd}=$ densidad del Drenaje, $\mathrm{Af}=$ asimetría, Ic= Índice de potencia de la corriente.

\begin{tabular}{|c|c|c|c|c|c|c|c|c|c|}
\hline & \multicolumn{7}{|c|}{ Parámetros Básicos } & & \\
\hline & $\begin{array}{c}\mathbf{A} \\
{\left[\mathrm{km}^{2}\right]}\end{array}$ & $\begin{array}{c}\mathrm{P} \\
{[\mathrm{km}]}\end{array}$ & $\begin{array}{c}\mathbf{L} \\
{[\mathrm{km}]}\end{array}$ & $\begin{array}{c}\mathbf{H} \\
{[\mathrm{msnm}]}\end{array}$ & $\begin{array}{c}\mathbf{h} \\
{[\mathrm{msnm}]}\end{array}$ & $\begin{array}{c}\mathbf{W} \\
{[\mathrm{km}]}\end{array}$ & On & & \\
\hline $\begin{array}{l}\text { CUENCA RÍO } \\
\text { GUALILÁN }\end{array}$ & 370 & 98.8 & 24.35 & 2190 & 1622.52 & 15.2 & 4 & & \\
\hline \multirow[t]{3}{*}{$\begin{array}{l}\text { CUENCA RÍO } \\
\text { LA CANTERA }\end{array}$} & 166 & 68.6 & 19.61 & 2187 & 1188 & 8.63 & 6 & & \\
\hline & \multicolumn{7}{|c|}{ Parámetros Derivados } & & \\
\hline & $K c=0,28 \times \frac{P}{\sqrt{A}}$ & $\begin{array}{c}\boldsymbol{R} \boldsymbol{e}=\sqrt{(4 A / \pi)} / L \\
\text { Schumm }(1956)\end{array}$ & $\begin{array}{l}\boldsymbol{F} \boldsymbol{f}=\frac{A}{L^{2}} \\
\text { Horton (1932) }\end{array}$ & $\begin{array}{l}S=L c p / L \\
\text { Schumm (1977) }\end{array}$ & $\begin{array}{l}\text { Pendiente } \\
\text { cuenca }(\%)\end{array}$ & $\begin{array}{l}\text { Pendiente río } \\
\text { Principal (\%) }\end{array}$ & $\begin{array}{l}\boldsymbol{D} \boldsymbol{d}=\frac{L t c}{A} \\
\text { Horton (1932) }\end{array}$ & $A \boldsymbol{f}=100(A r / A t)$ & $\begin{array}{l}\text { Ic }=A x \tan (\text { pend }) \\
\text { Moore et al. (1991) }\end{array}$ \\
\hline $\begin{array}{l}\text { CUENCA RÍO } \\
\text { GUALILÁN }\end{array}$ & 1.45 & 0.89 & 0.62 & 2.45 & 12.4 & 1.8 & 2.39 & 35 & 235.45 \\
\hline $\begin{array}{l}\text { CUENCA RÍO } \\
\text { LA CANTERA }\end{array}$ & 1.5 & 0.74 & 0.43 & 1.17 & 20.55 & 4.7 & 1.89 & 41 & 454.9 \\
\hline
\end{tabular}

principal colector con pendiente del $4.7 \%$, con una máxima de $9 \%$ en sus tramos medio y distal. En ambas cuencas se aprecia que los mayores valores de pendiente se encuentran en los sectores montañosos que las limitan, principalmente en la sierra de La Invernada donde superan el $30 \%$. En esta sierra, los mayores valores de pendiente se registran en su tramo sur, donde superan el 35 $\%$ por estar controlado su flanco oriental por el SFLC.

La curva hipsométrica (Strahler, 1964) permite conocer la distribución de masa en la cuenca desde aguas arriba hacia abajo. Scheidegger y Ai (1986) señalaron que el levantamiento (uplifting) tectónico es un proceso continuo y que, a lo largo de la historia de una cuenca, hay una tendencia a equilibrar las fuerzas antagónicas de construcción tectónica y degradación por erosión $\mathrm{u}$ otros mecanismos. Si un paisaje muestra un carácter permanente, estos dos procesos opuestos están en equilibrio dinámico. Este autor atribuyó las diversas formas de la curva hipsométrica a los niveles de actividad de los procesos citados. Las curvas hipsométricas, obtenidas para las cuencas en el área de estudio, indican para la cuenca del río Gualilán una baja actividad tectónica en sus tramos medio e inferior, aunque en su cabecera en la sierra de La Invernada muestran una mayor actividad. La curva hipsométrica obtenida para la cuenca del río La Cantera sugeriría una actividad tectónica mayor tanto en su cabecera como en su desembocadura en el río San Juan (Figura 8a y 8b).

Una de las técnicas existentes para cuantificar los procesos de erosión sobre cuencas es mediante la determinación de los índices de erosión (Ic), conocidos por sus siglas en inglés como SPI (Stream Power Index), que miden las tasas de erosión en unidades de potencia (vatio). Wilson y Lorang (1999) señalaron que este índice mide el poder erosivo (en vatios) del flujo del agua, considerando que el caudal de un río es proporcional al área de captación específica $\left(\mathrm{m}^{2}\right)$. El mismo predice la erosión neta en áreas de perfil convexo y de convexidad tangencial (zonas de convergencia y de aceleración de flujo), así como la depositación neta de sedimentos en áreas de perfil cóncavo, que son las zonas donde disminuye la velocidad del flujo.

El índice de potencia de la corriente (Ic) puede usarse para describir la erosión potencial del flujo en el punto dado de la superficie topográfica. A medida que aumentan las áreas de captación y el gradiente de pendiente, aumenta la cantidad de agua que es contribuida por las áreas ascendentes y la velocidad del flujo de agua, por lo que aumenta el riesgo de erosión y el índice de potencia de la corriente. Los valores elevados corresponden a zonas montañosas de alta pendiente donde existe una mayor incisión. Los valores bajos sugieren 


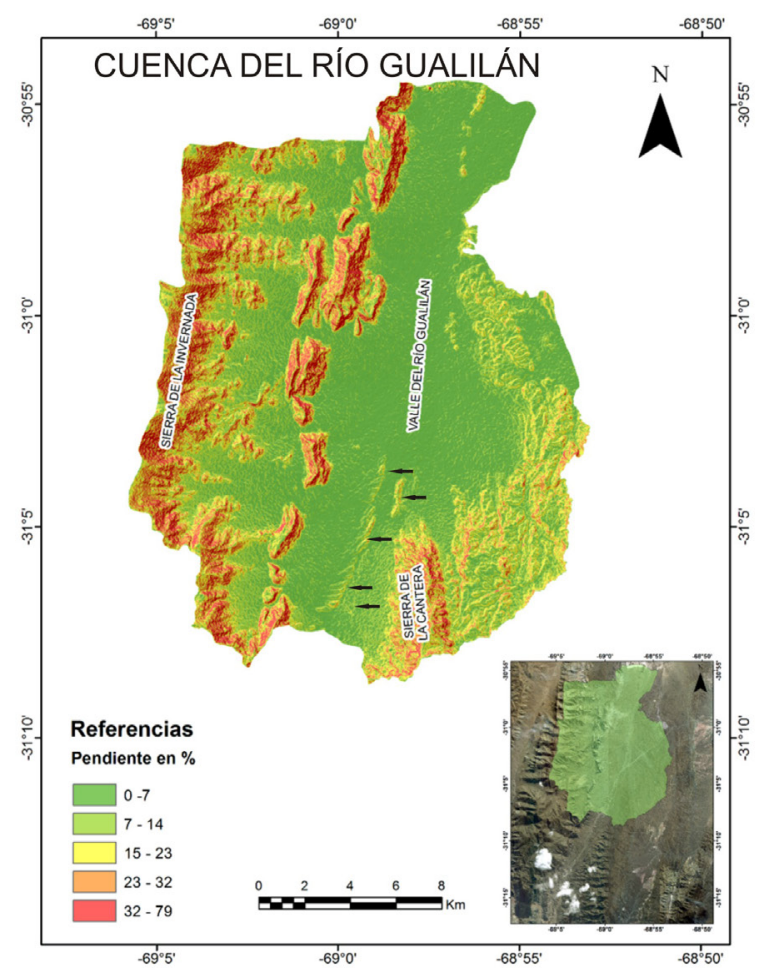

a)

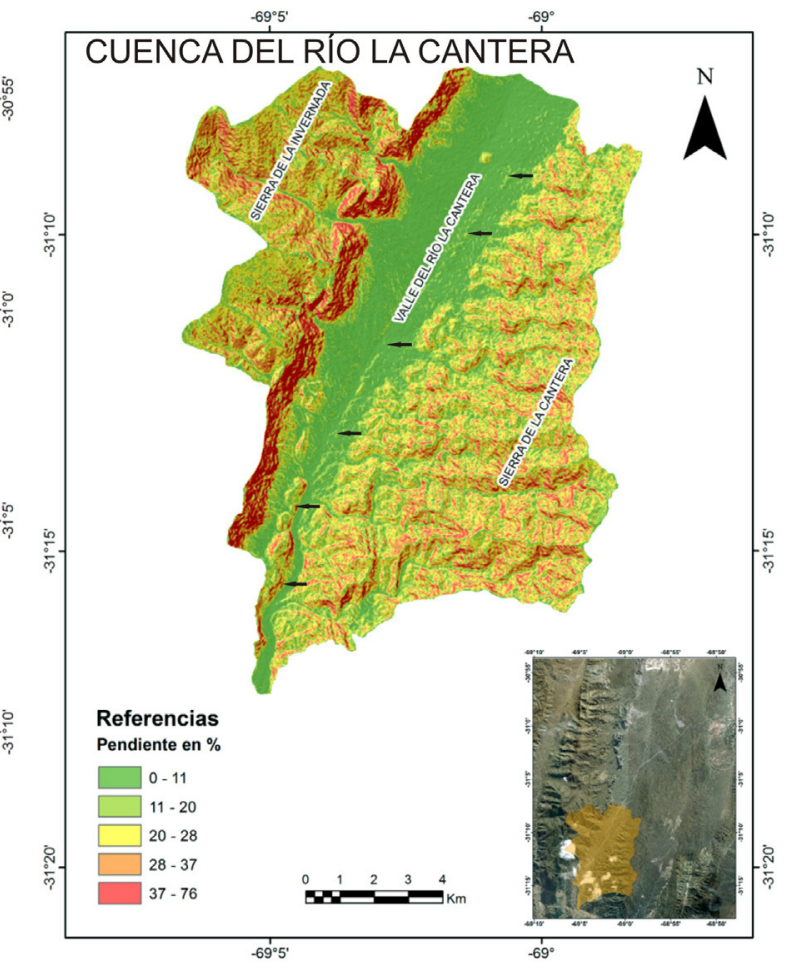

b)

Figura 7 a) Mapa de pendientes de la cuenca del río Gualilán; b) Mapa de pendientes de la cuenca del río La Cantera. Las flechas señalan la posición de los trazos de falla con actividad tectónica cuaternaria pleistocena tardía-holocena (Sistema de Falla La Cantera). Es posible apreciar las elevadas pendientes en el flanco oriental de la sierra de La Invernada ( 35 \%) que hacia el sur corresponden al trazo activo del Sistema de Falla La Cantera.

zonas de baja pendiente, llanuras aluviales o áreas de lenta subsidencia (Finnegan et al., 2007).

El índice medio de la potencia de la corriente obtenido para la cuenca del río Gualilán (Tabla 1, Figura 9a) es notablemente menor que el obtenido para la cuenca del río La Cantera (Tabla 1, Figura 9b). Es importante destacar que el río principal de la cuenca del río Gualilán posee un índice de potencia muy bajo (prácticamente no se aprecia el cauce colector principal). Tampoco se aprecian sus tributarios en el piedemonte ni en el sector más bajo del valle y solamente el sector montañoso muestra valores elevados, tal como se observa en la Figura 9a. Por el contrario, el río La Cantera tiene un índice más elevado; en la Figura 9b claramente se aprecia que los mayores valores se registran en los sectores montañosos aunque también en el colector principal y sus tributarios en los piedemontes afectados por las fallas con actividad tectónica cuaternaria. Cuando sobre una cuenca de drenaje incide una deformación tectónica, el diseño de la red se verá afectado en mayor o menor medida según sea la intensidad de la deformación y la capacidad que posea la cuenca para acomodarse a esa deformación.

La sinuosidad de un frente montañoso $(\mathrm{S})$ se define como un índice que refleja el balance entre los procesos erosivos, que tienden a formar abanicos o flujos sobre un frente montañoso, y los procesos tectónicos, que tienden a generar frentes de montaña rectos coincidentes con bordes de falla activos (Keller y Pinter, 2002). El valor numérico se obtiene por medio de la relación entre la longitud de la línea que sigue la topografía $L j$ y la longitud de la línea recta que une los dos extremos del frente montañoso $L s$, por lo tanto: $S=L j / L S$ (Bull, 2007).

Comúnmente el valor $\mathrm{S}$ es menor de 3 y alcanza un mínimo de 1. Así, mientras más cercano esté $\mathrm{S}$ de 1, más expresión morfológica 

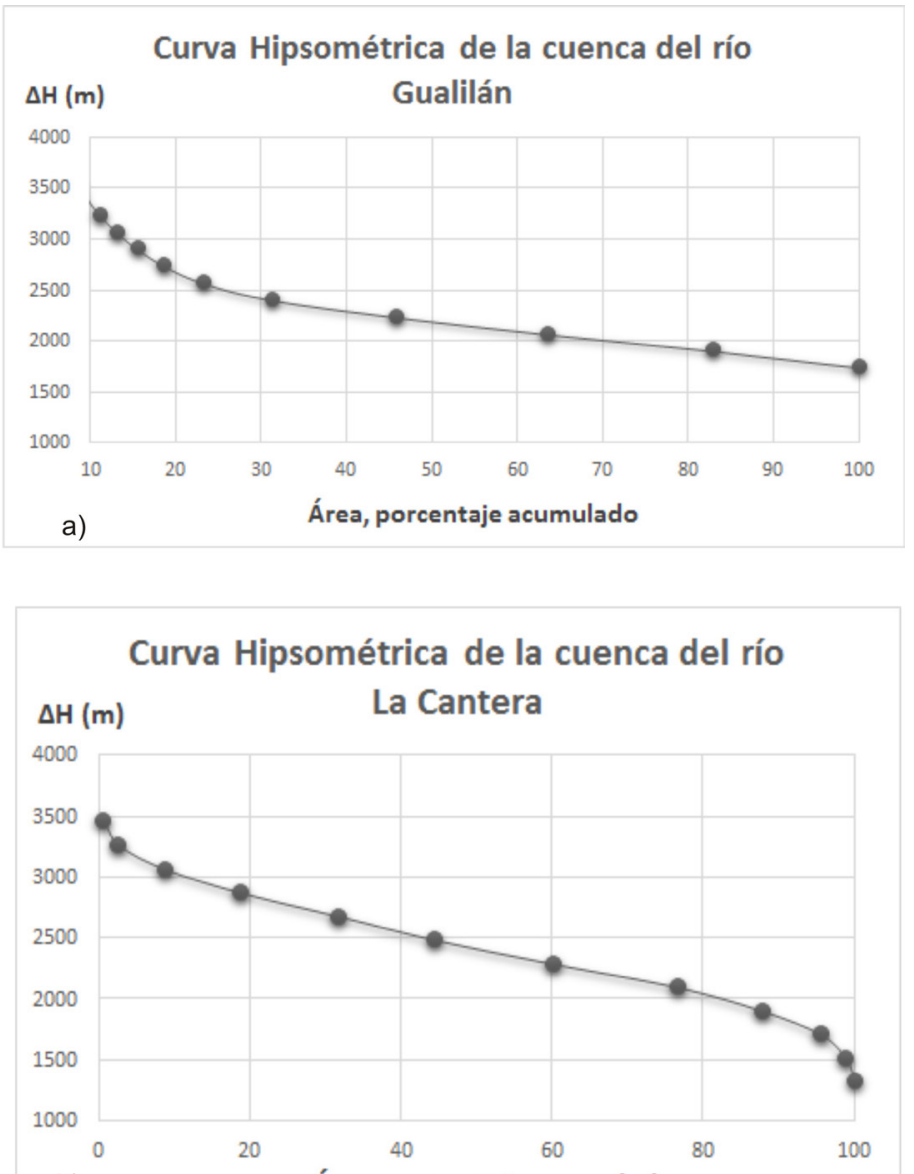

b)

Área, porcentaje acumulado

Figura 8 a) Curva hipsométrica del río Gualilán, correspondiente a un río en equilibrio o maduro; b) Curva hipsométrica del río La Cantera indicando una mayor actividad tectónica.

tendrá, puesto que será más recto y definido, indicando que los procesos tectónicos predominan sobre los erosivos.

La sierra de La Invernada en la cuenca del río Gualilán posee un índice de sinuosidad (S2) elevado (mayor a 2), con desarrollo de extensos abanicos aluviales, algunos con morfologías del tipo retrollenado desde el frente montañoso y coalescencia en algunos sectores, mientras que el índice S1 obtenido en la cuenca del río La Cantera para la misma sierra es cercano a 1, indicando un frente montañoso rectilíneo, con desarrollo de abanicos coluviales y conos coluviales (Tabla 1, Figura 10).

El índice de asimetría de una cuenca (Af) intenta cuantificar la ausencia o existencia de basculamientos a escala de la cuenca de drenaje.
Cuanto más se aproxime éste al $50 \%$, menor será la influencia de la actividad tectónica; cuanto más se diferencie del $50 \%$, mayor influencia tuvo o tiene la incidencia de la actividad tectónica: es decir, una mayor intensidad de basculamiento. Para el caso de la cuenca del río Gualilán, el valor del índice de asimetría obtenido es $35 \%$, mientras que para la cuenca del río La Cantera el valor es $41 \%$, indicando cuencas un poco asimétricas, principalmente la del río Gualilán (Figura 10).

El índice de gradiente de la corriente (SL) o perfil de Hack (Hack, 1973), busca identificar anomalías morfométricas a través de perfiles longitudinales de cualquier drenaje y su correlación con factores controlantes tales como la litología o tectónica. Se calcula a partir del producto del gradiente $(\Delta \mathrm{H} / \Delta \mathrm{L})$ de un tramo recto del río por 


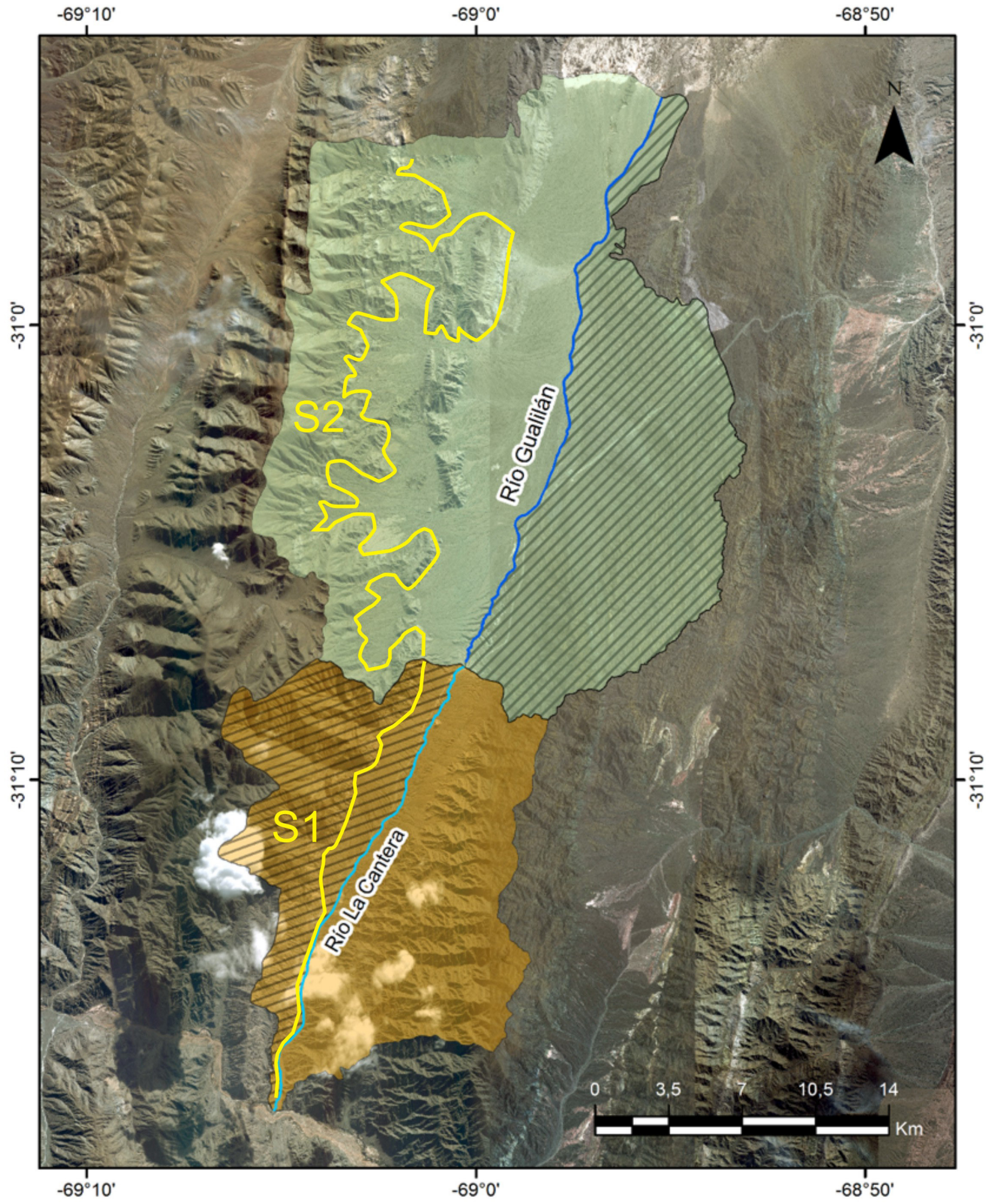

Figura 9 Mapa que muestra la asimetría de las cuencas y la variación de sinuosidad del frente montañoso de la sierra de La Invernada. Es posible observar la mayor asimetría de la cuenca del río Gualilán respecto de la del río La Cantera. Por otra parte, el frente montañoso en la cuenca del río La Cantera (S1) es marcadamente rectilíneo, indicando un frente activo, mientras que en la cuenca del río Gualilán, el frente montañoso (S2) es sinuoso y posee engolfamientos y forma extensos abanicos aluviales, sugiriendo un frente menos activo. 

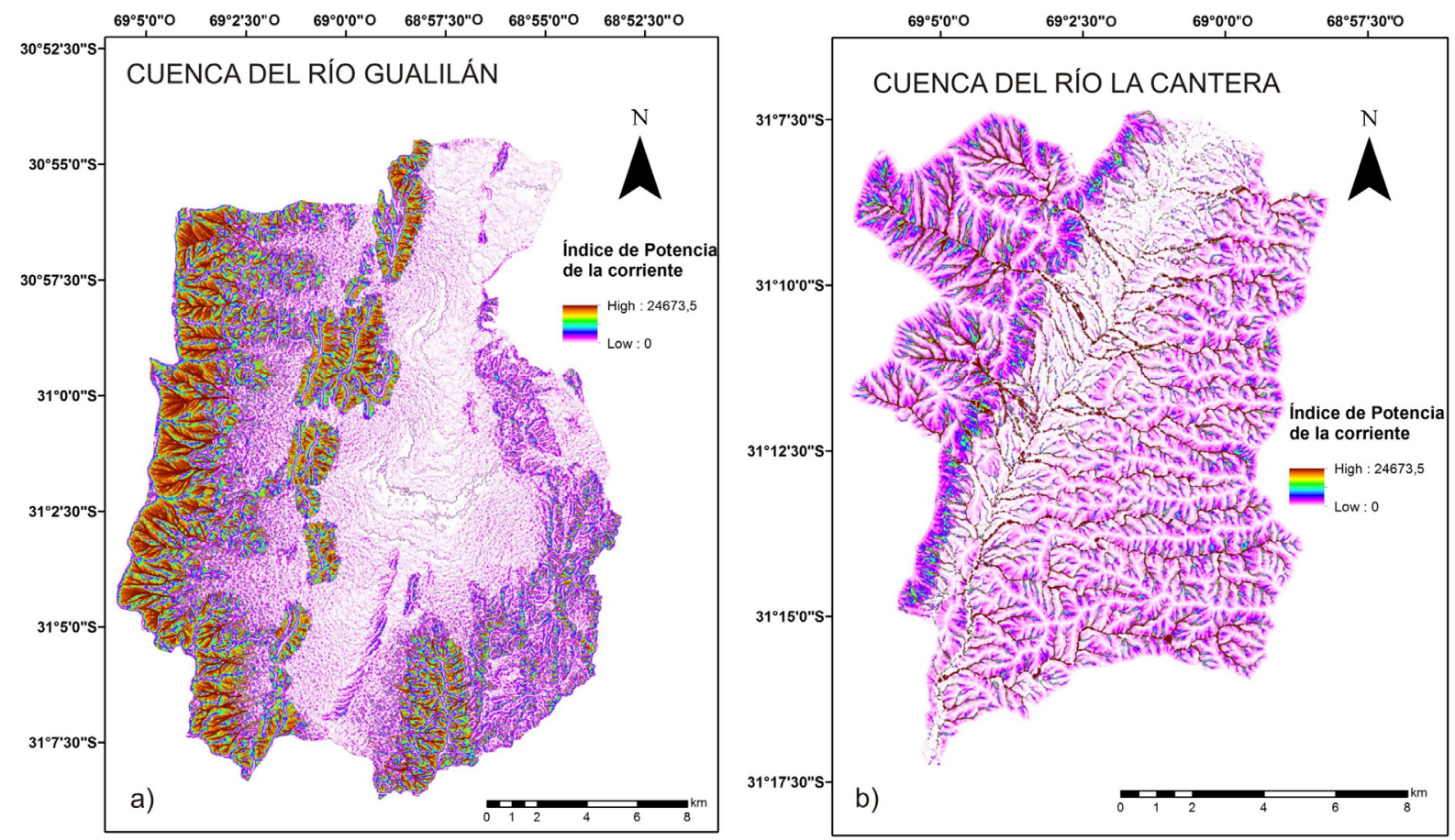

Figura 10 a) Índice de potencia de la corriente para la cuenca del río Gualilán. Es posible observar que los valores más elevados se encuentran en el flanco oriental de la sierra de La Invernada, cuya altura supera los $3500 \mathrm{msnm}$, y en los cordones calcáreos elevados por falla; b) Índice de potencia de la corriente para la cuenca del río La Cantera. Se puede apreciar un mayor poder erosivo para esta cuenca en los cordones montañosos que la limitan (principalmente en sector central de la sierra de La Invernada, cuyo flanco oriental se encuentra controlado por falla del mismo nombre). Sin embargo, se observan también valores elevados en ambos piedemontes afectados por las distintas secciones de falla con actividad tectónica cuaternaria (SFLC).

la longitud total del río entre el centro del intervalo de interés hasta la cabecera del drenaje (L). El índice SL, en una cuenca homogénea, permanecerá aproximadamente constante a lo largo de su longitud. Este índice parte del supuesto de que la pendiente de un río en equilibrio disminuye aguas abajo y el perfil longitudinal de un río se aproxima a una recta en un gráfico semi-logarítmico (Mackin, 1948). Por lo tanto, las variaciones en el índice de gradiente de corriente, a lo largo de un río, típicamente reflejan cambios que son atribuibles a controles litológicos (por ejemplo, rocas más resistentes que causan gradientes más pronunciados) o controles tectónicos (zonas de levantamiento diferencial o subsidencia). Los ríos que no son perturbados tectónicamente suelen desarrollar un perfil longitudinal cóncavo de cambio suave. Las desviaciones del gradiente de un río, a partir de esta forma lisa ideal, pueden reflejar variaciones en la litología o en la tasa de elevación de la roca del lecho del río. Se predice que los ríos tectónicamente perturbados se acercan rápidamente a un perfil gradual una vez que cesa la perturbación (Snow y Slingerland, 1987). Así, las perturbaciones en los perfiles de los ríos, especialmente cuando no están correlacionadas con los contrastes litológicos, pueden interpretarse como respuestas a la actividad tectónica. Es decir, un perfil longitudinal que se desvía significativamente de una forma suave y cóncava, y donde tales desviaciones no se relacionan sistemáticamente con variaciones en la resistencia litológica, indica un perfil que no está en equilibrio. Sin embargo, algunos autores como Phillips y Lutz (2008) señalaron que dado que los procesos de no equilibrio pueden producir un perfil de este tipo, la presencia de un perfil cóncavo suave, sin evidencia que así lo indique, no necesariamente implicará un estado de equilibrio. 
Una manera de cuantificar las perturbaciones en los perfiles longitudinales se basa en definir los cambios en el índice de gradiente de la corriente a lo largo del curso del río. Para una corriente gradual, un diagrama semi-logarítmico del perfil longitudinal dará una línea casi recta. Al comparar los perfiles de Hack obtenidos para cada cuenca analizada, queda en evidencia que la cuenca del río Gualilán parece estar más cerca del estado de equilibrio (Figura 11 a y 1 lb), mientras que la cuenca del río La Cantera presenta mayores variaciones en el índice de gradiente de la corriente a lo largo del curso principal N-S e

SL Cuenca del río Gualilán (Tramo N-S)

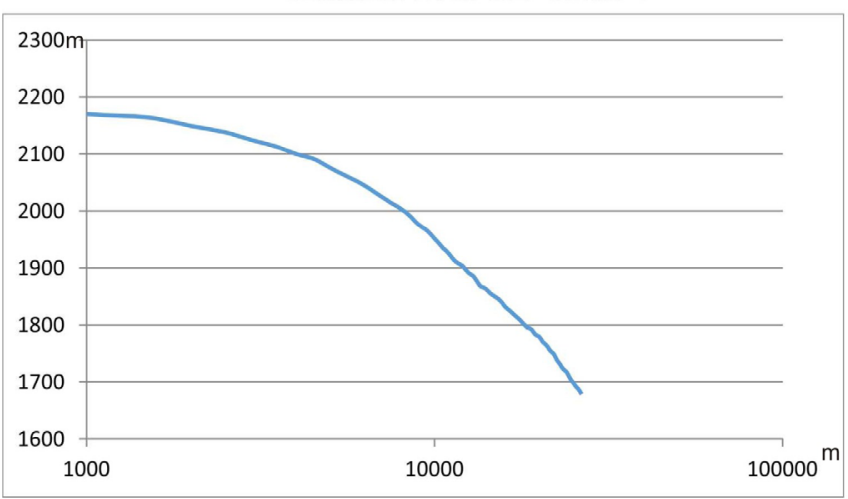

a)

SL Cuenca del río La Cantera (Tramo N-S)

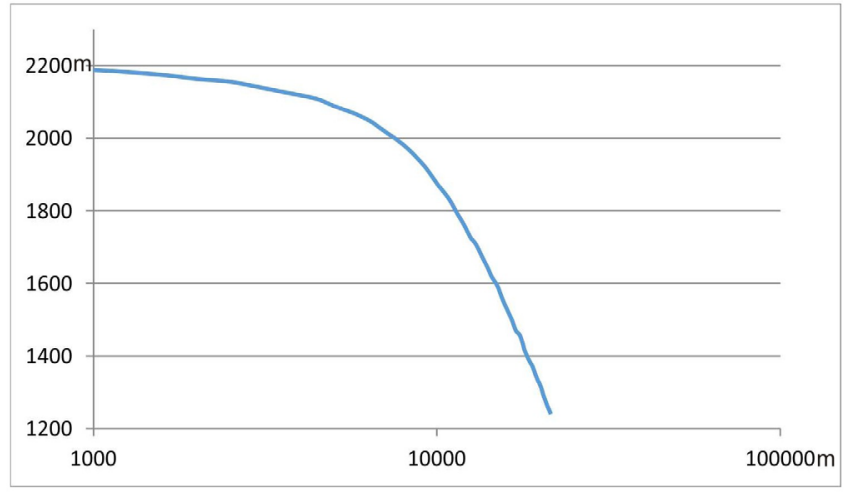

c) incluso al considerar la longitud total del río desde sus cabeceras en la sierra de La Invernada, probablemente debido a la actividad tectónica que indujo deformación en su flanco oriental, aumentando la intensidad de los regímenes de erosión (Figura 11c y 11d). Cabe destacar que los colectores principales (N-S) en ambas cuencas son consecuentes, ya que siguen la estructura y estratificación de las rocas del Neógeno que se ubican en el fondo del valle, por lo que no muestran variaciones en la litología. También son rocas con similares características las ubicadas a lo largo de toda la sierra de La Invernada (grauvacas, pelitas

SL Cuenca del río Gualilán (cabeceras sierra de La Invernada)

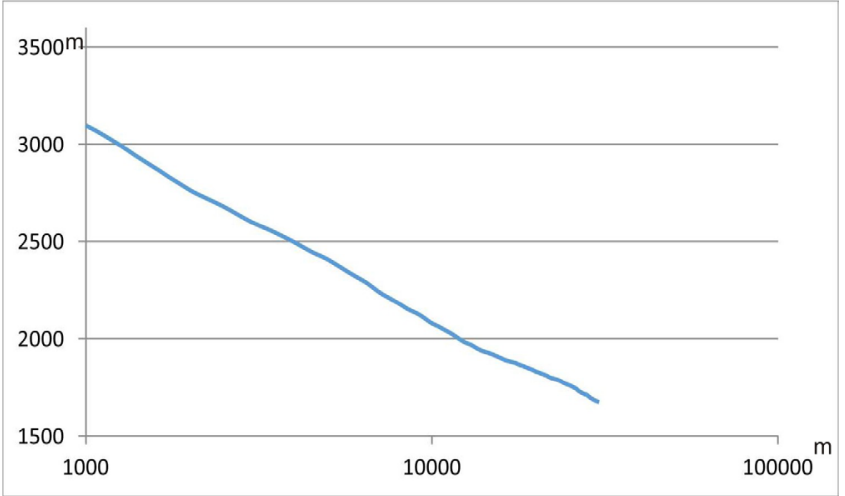

b)

SL Cuenca del río La Cantera (cabeceras sierra de La Invernada)

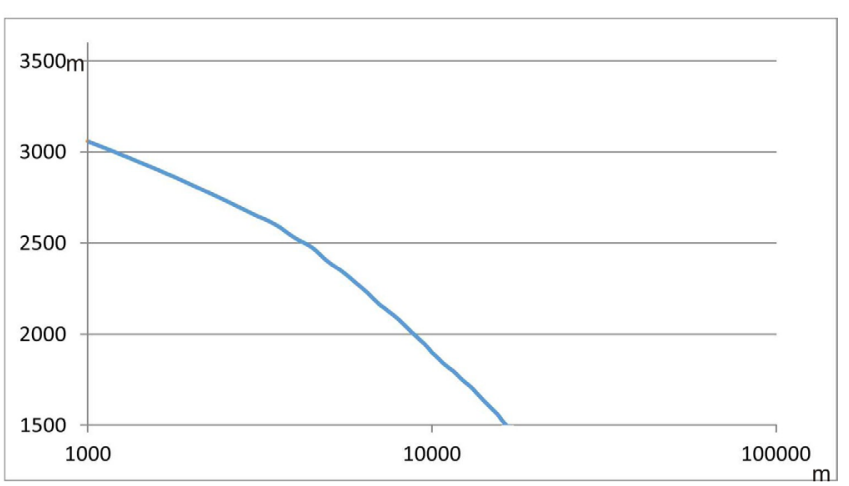

d)

Figura 11 a) Representación gráfica del perfil longitudinal (SL) del río Gualilán en su tramo N-S, ligeramente convexo indicando que el mismo aún no alcanza el equilibrio; b) Por el contrario, si se considera el río desde sus cabeceras en la sierra de La Invernada, el mismo forma casi una recta, indicando que se encuentra más cerca del estado de equilibrio; c y d) Perfiles SL del río La Cantera, los cuales muestran un río lejos de su equilibrio, indicando la influencia de la actividad tectónica en el sector, especialmente al considerar su tramo N-S, el cual es marcadamente convexo. 
y algunos afloramientos calcáreos) y de la sierra de La Cantera (grauvacas y pelitas).

\subsection{SWATH PROFILES}

Según Scotti et al. (2014), a escala regional las características topográficas de un área se pueden describir mediante la variación espacial de elevaciones mínimas, promedio y máximas. La máxima topografía es representada por una superficie conocida como la envolvente que conecta los picos y muestra una topografia sin incisión. La topografía mínima es descrita como una sub-envolvente que corresponde a las elevaciones del fondo de los valles, y el promedio de la topografía tiende a representar el patrón general del paisaje a escala regional.

El relieve local es calculado entre la sustracción de la topografía máxima y mínima y cuantifica la incisión fluvial en un área dada. En paisajes tectónicamente activos, regiones con valores anómalamente altos del relieve local comúnmente coinciden con regiones de incisión por corrientes activas en respuesta a un levantamiento de roca (Molin et al., 2004). La variación del relieve local, en un área donde el clima es casi constante en toda la región y no hay contrastes litológicos, indica que los ríos responden a diferentes impulsos tectónicos (Scotti et al., 2014).

Los perfiles en franja o swath profiles de las cuencas estudiadas, fueron realizados mediante el software SAGA GIS para los ríos colectores principales y para el río principal, considerado desde sus cabeceras en la sierra de La Invernada. Estos perfiles fueron elaborados a partir de SRTM 12,5 (DEM) y un ancho de franja de $1 \mathrm{~km}$. Al analizar el perfil obtenido a lo largo del río Gualilán, en su tramo N-S (Figura 12a), no se aprecian grandes variaciones en el relieve local, producto de que la topografía máxima y la mínima poseen valores
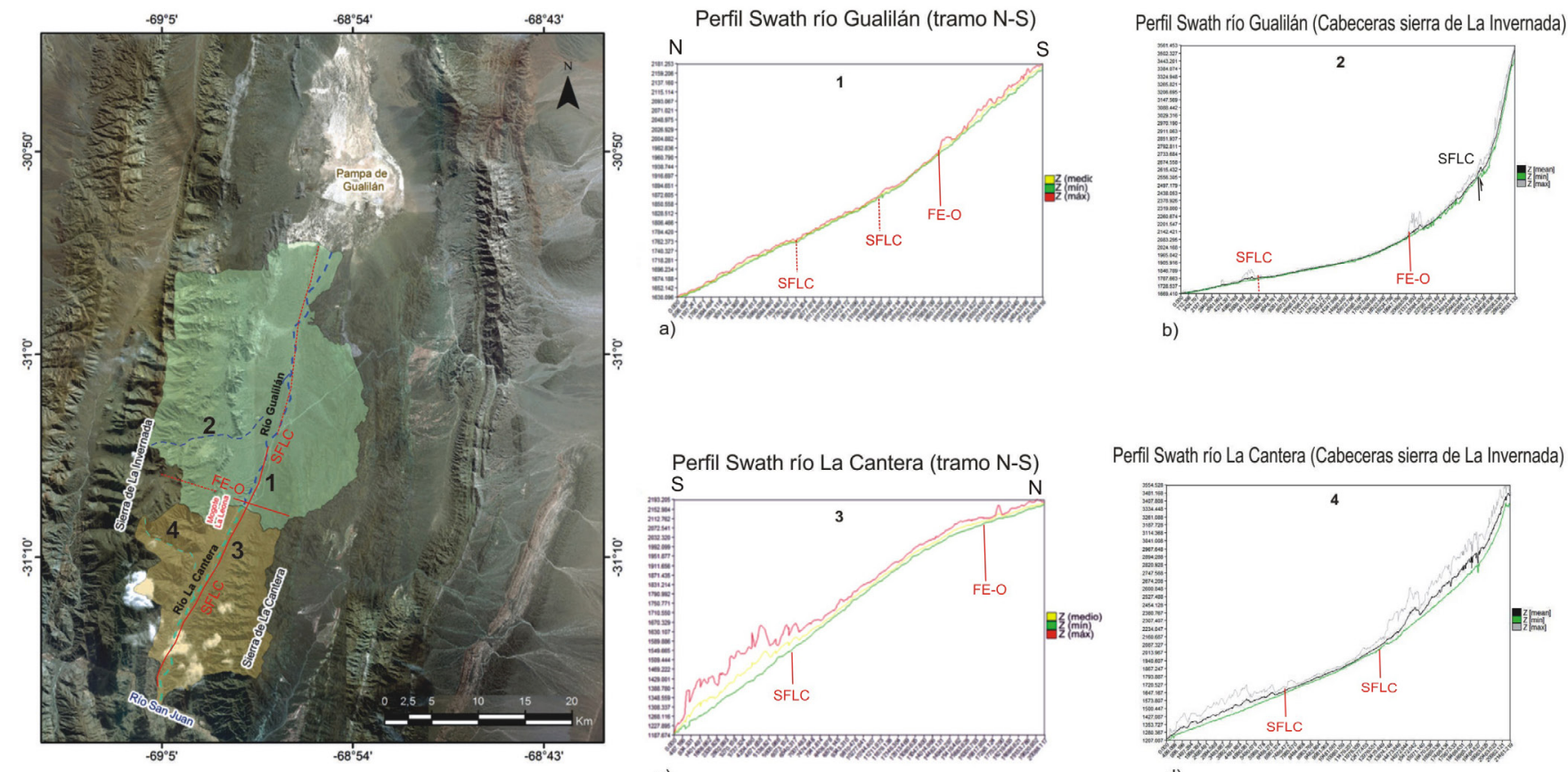

b)

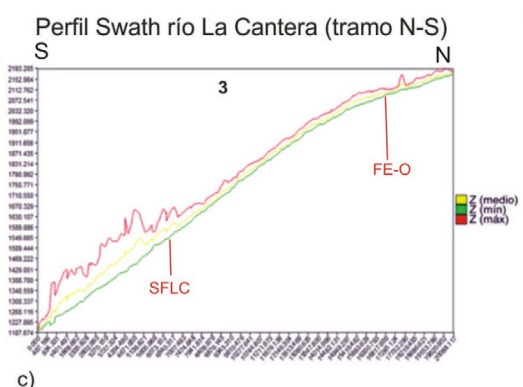

Perfil Swath rio La Cantera (Cabeceras sierra de La Invernada)

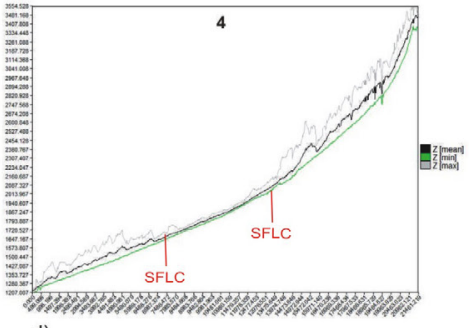

d)

Figura 12 Perfiles de franja (Swath profiles) para los ríos a) y b) Gualilán y c) y d) La Cantera. Se puede apreciar que las mayores diferencias entre las alturas máximas y mínimas de sus perfiles longitudinales se producen en los tramos superiores de ambos ríos y en el tramo inferior del río La Cantera, en coincidencia con el trazo del Sistema de Falla La Cantera (SFLC) y de la falla E-O (F E-O), ambos señalados por flechas. Los trazos activos se indican con línea roja y los inactivos, con línea negra. Con línea de trazos se señala la estructura inferida coincidente con el eje del valle, la cual posee evidencias aisladas de actividad hacia el norte, en las proximidades a la Pampa de Gualilán. 

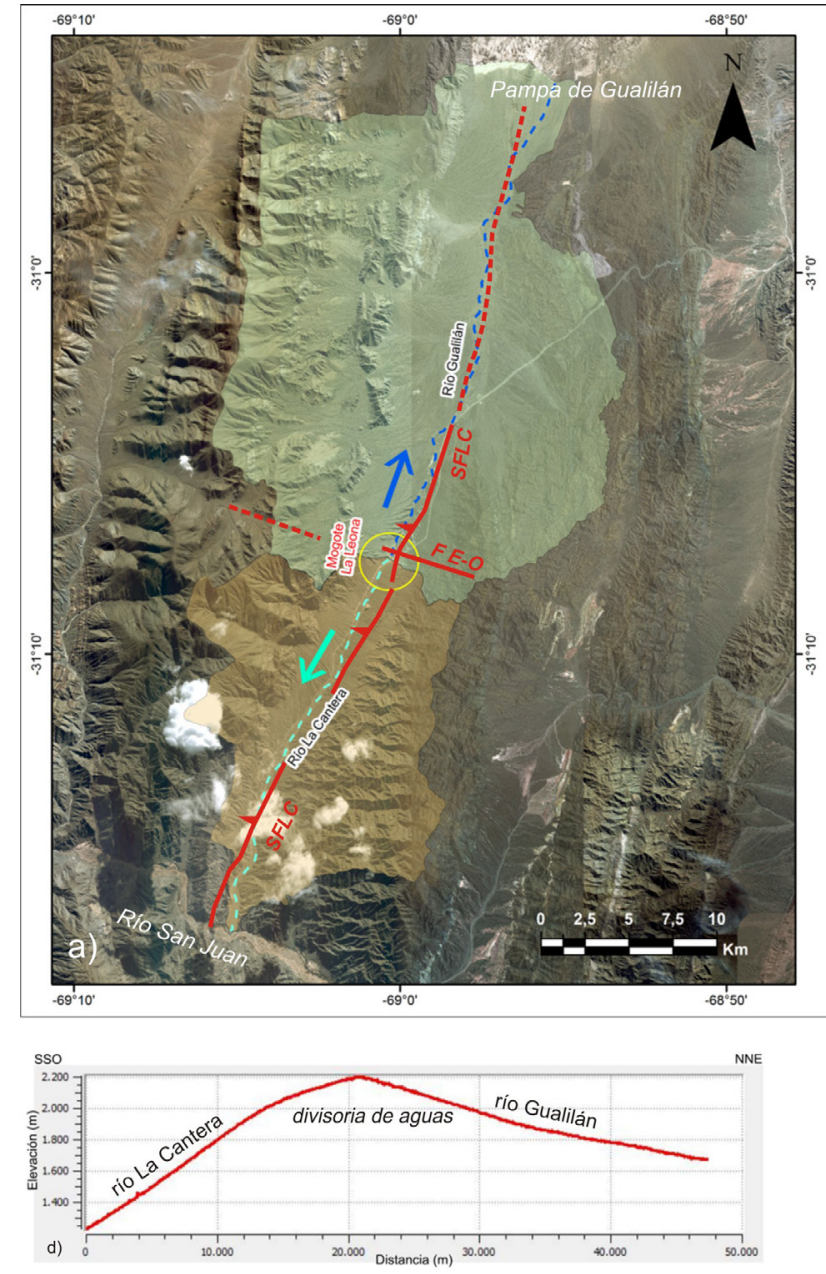
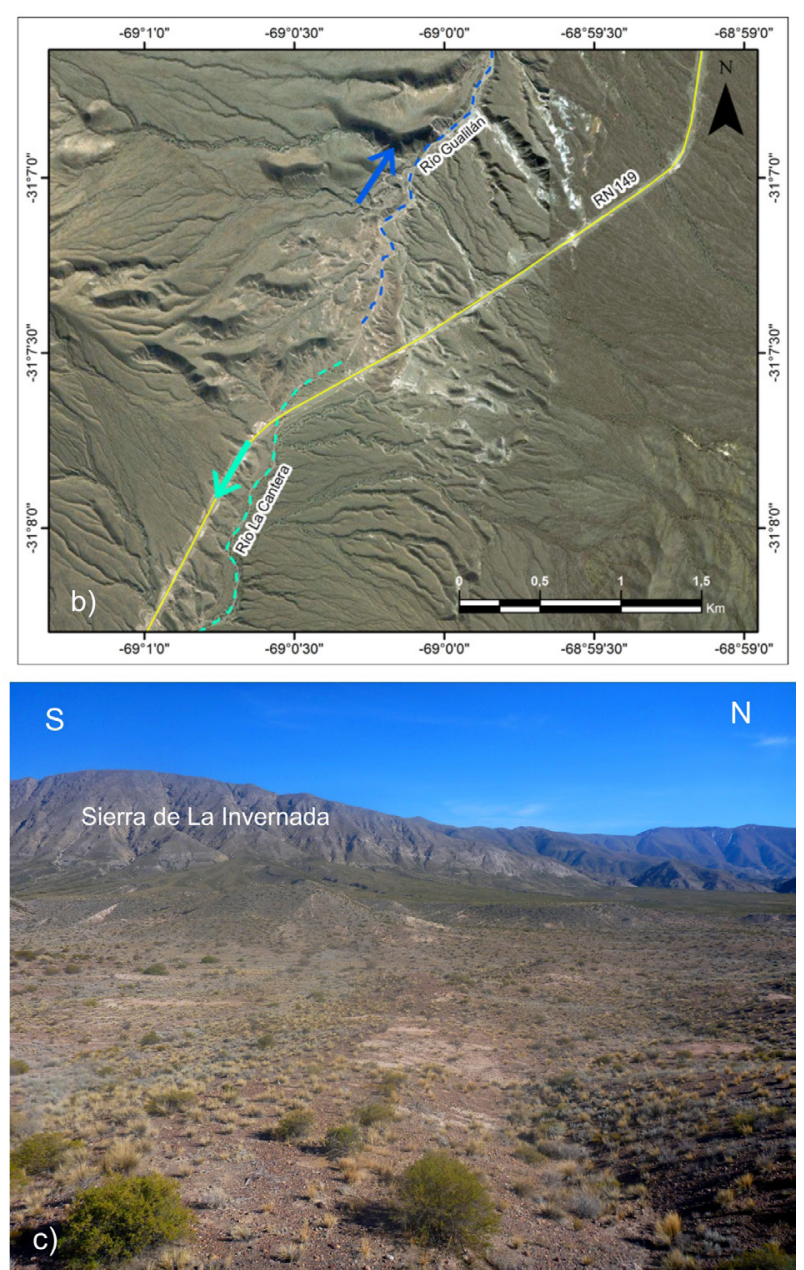

Figura 13 a) Imagen satelital en la que se indican ambas cuencas, sus direcciones de flujo y la divisoria de aguas, indicada por un círculo amarillo, y las secciones de falla con evidencia de actividad tectónica cuaternaria; b) Detalle de la divisoria o portezuelo en el que se aprecian formas redondeadas en sedimentos poco consolidados, c) afloramientos de rocas sedimentarias fácilmente erosionables del Neógeno en el sector del portezuelo, d) perfiles longitudinales de ambos ríos desde su portezuelo o divisoria de aguas (Mogote La Leona), en los que se aprecia el estado de desequilibrio, una mayor pendiente y desnivel del río La Cantera (potencial captor) respecto del río Gualilán (potencial capturado).

similares y por lo tanto las líneas se mantienen prácticamente juntas. Sólo en la zona de la cabecera del río (como lo indican las flechas en la figura de la izquierda y en el perfil), se hace más evidente una variación, debido a que se separan los valores de $\mathrm{Z}$ máximo y $\mathrm{Z}$ mínimo. Esto indicaría una mayor incisión en este sector con respecto al resto del cauce. Posiblemente esto se debe a la presencia de la falla E-O ubicada en la cabecera, ya que este tramo del río es el único que muestra terrazas de erosión. Como se señaló en párrafos anteriores, el perfil longitudinal del río es ligeramente convexo, lo que indica que aún no se alcanza un estadio de equilibrio. Al comparar el perfil de la figura 12a con el obtenido, considerando el río desde sus nacientes en la sierra de La Invernada (Figura 12b), es posible apreciar que las mayores variaciones se presentan en el sector montañoso, al atravesar los cordones calcáreos elevados por falla.

Por otro lado, el perfil de franja del río La Cantera (Figura 12c), notoriamente convexo, muestra que la incisión fluvial es bastante mayor que la del río Gualilán a lo largo de todo el curso, principalmente en su cabecera cerca del mogote La Leona, donde se ubica la falla inversa E-O y haciéndose todavía mayor en el tramo inferior 
donde la falla La Cantera atraviesa su llanura de inundación para afectar el flanco oriental de la sierra de La Invernada y en la desembocadura, en el sector donde se identificaron las terrazas aluviales impares. Por otro lado, el perfil de la Figura $12 \mathrm{~d}$ que considera la longitud del río desde las cabeceras en la sierra de La Invernada, muestra las mayores diferencias de elevación en el sector montañoso elevado por el SFLC y también en la desembocadura del río La Cantera en el río San Juan, en el sector en el que se ubican las terrazas fluviales.

\section{Discusión}

Del análisis de los perfiles de equilibrio obtenidos para ambas cuencas fluviales, se observa que el cambio en la pendiente de ambos perfiles no correspondería a un control litológico ya que ambas cuencas se desarrollan en forma paralela a las unidades litológicas ubicadas en el área de estudio. Por lo tanto, se sugiere un control estructural de las distintas secciones con actividad tectónica holocena pertenecientes al Sistema de Falla La Cantera. No debe descartarse además un control por estructuras no aflorantes de rumbo E-O, NE o NO como otras posibles causantes de estos knickpoints y convexidades en los perfiles de equilibro.

El perfil del río Gualilán, al considerar solamente el cauce colector de rumbo N-S, no muestra una línea curva característica cóncava, sino que constituye una recta con una pendiente elevada prácticamente constante, aunque con una suave disminución de pendiente en su tramo medio (Figura 5a). Además, al considerar el río desde sus nacientes en la sierra de La Cantera, se aprecia la forma de una curva cóncava, representativa de un estado de equilibrio. Es posible apreciar el cambio de curvatura en el perfil al salir del confinamiento montañoso donde es mayor la erosión y al entrar al valle donde disminuye la pendiente y aumenta la depositación. Por otro lado, el río La Cantera muestra un perfil convexo con una fuerte pendiente al salir del cordón montañoso y knickpoints en su tramo superior e inferior. Al considerar el río desde sus cabeceras en la sierra de La Invernada, el perfil del río es ligeramente cóncavo, indicando un río más próximo al equilibrio que si sólo se considera el colector N-S. En ambos casos se reconoció, en las imágenes satelitales y en los perfiles de franja, que la traza del sistema de falla La Cantera estaría generando estas variaciones en la pendiente producto del movimiento de esta estructura con actividad holocena. También la falla inversa de rumbo O-E y vergencia al norte estaría controlando los perfiles longitudinales, ya que compartimenta el valle longitudinal en dos cuencas fluviales colineales y opuestas.

Los valores de pendiente media obtenida para la cuenca del río La Cantera (20.55\%), cuyo río principal posee una pendiente de $4.7 \%$, son notoriamente mayores que los de la cuenca del río Gualilán (pendiente media $12.4 \%$ y pendiente del río principal $1.8 \%$ ). Por lo tanto, mayor será el poder erosivo para la primera. Las pendientes se incrementan en el flanco oriental de la sierra de La Invernada, con valores que superan el $30 \%$ debido a un fuerte control estructural (Figuras 1b, $6 a$ y $6 b)$

La cuenca del río Gualilán se encontraría en una fase que iría de moderada a baja actividad tectónica como lo demuestra la curva hipsométrica cóncava hacia arriba. Solamente en sus cabeceras se aprecia una evidencia de moderada actividad debido al frente de cabalgamiento que levanta dicho cordón montañoso. Por el contrario, la cuenca del río La Cantera señalaría mayor actividad tectónica, principalmente en sus tramos superior y distal, debido al control que ejerce sobre la sierra de La Invernada el trazo activo del SFLC.

A partir del índice de potencia de la corriente (Stream Power Index) y de los mapas obtenidos, queda en evidencia que el río La Cantera y sus tributarios poseen mayor potencial de erosión en prácticamente toda la cuenca. Sin embargo, no ocurre lo mismo con la cuenca del río Gualilán, en la que el río principal posee valores muy por debajo de este índice, por lo que se interpreta un menor potencial de erosión. Ambas cuencas 
poseen valores elevados en el sector montañoso, principalmente en la sierra de La Invernada, aunque los mayores índices se registran en el tramo sur de la sierra, en la que el cabalgamiento que la eleva posee evidencia de actividad tectónica cuaternaria.

Los valores de índice de asimetría para la cuenca del río Gualilán muestran una cuenca fluvial un poco más asimétrica (35\%) que la del río La Cantera $(41 \%)$. Por otra parte, el frente montañoso de la sierra de La Invernada en el sector sur es marcadamente rectilíneo, con un índice de sinuosidad cercano a uno (con elevada actividad tectónica) respecto de la misma sierra hacia el norte (en la cuenca del río Gualilán), debido al control del Sistema de Falla La Cantera, constituido por dos cabalgamientos paralelos con vergencia al este que colocan rocas del Paleozoico sobre sedimentitas neógenas y éstas últimas sobre depósitos aluviales cuaternarios. En este tramo se desarrollan abanicos coluviales en la porción norte de la cuenca y conos coluviales en el sector sur, donde se estrecha notablemente el valle (pasa de $3.5 \mathrm{~km}$ al norte, a solamente $400 \mathrm{~m}$ en el sur). La menor asimetría para la cuenca del río La Cantera podría deberse al mayor acortamiento que muestra la Precordillera Central en el área debido a la presencia de bloques imbricados sobrecorridos y plegados con vergencia oriental y que implican una pila de sedimentos desde ordovícicos a neógenos e incluso cuaternarios en una distancia horizontal muy reducida $(\sim 3 \mathrm{~km})$. Por el contrario, para la cuenca del río Gualilán, se aprecia un acortamiento menor, con un frente montañoso sinuoso (con baja actividad tectónica), en el que ha actuado intensamente la erosión fluvial, desarrollando un piedemonte extenso e importantes abanicos aluviales provenientes de la sierra. Estos amplios abanicos aluviales coalescen en el sector distal, donde son afectados por uno de los trazos del SFLC que desvía los cauces hacia el norte, desarrollando pendientes anómalas (Perucca et al., 2015). El valle posee un ancho entre 4 y $8 \mathrm{~km}$ en este sector central.
Las variaciones en el índice de gradiente SL más pronunciadas en la cuenca del río La Cantera, a lo largo del curso principal, serían producto de un control netamente tectónico asignado al Sistema de Falla La Cantera y a la falla E-O ubicada en el mogote La Leona. Esto es sugerido por la convexidad de los perfiles semi-logarítmicos de Hack en ambas cuencas y por el análisis de imágenes satelitales en las que se observó que el Sistema de Falla La Cantera atraviesa el cauce del río. No hay variaciones litológicas en el eje del valle por el que discurren ambos colectores principales y tampoco se aprecian grandes variaciones en cuanto a competencia en las rocas aflorantes en los sectores montañosos que limitan la depresión.

Los perfiles de franja (swath profiles) permitieron identificar zonas localizadas de mayor incisión a lo largo del curso principal de las cuencas en estudio. Para el caso del río Gualilán, la zona de mayor incisión se da en el tramo superior del mismo, en las proximidades a la falla inversa O-E. En el río La Cantera, estas zonas se desarrollan en mayor medida en el tramo inferior y también en el superior. Esto estaría asociado nuevamente a la falla de rumbo O-E y al Sistema de Falla La Cantera, al atravesar en su tramo sur la llanura aluvial del río, por lo que ambas estructuras cuaternarias ejercen un fuerte control tectónico y no así otros factores, como el clima o la litología del sustrato, que son homogéneos en ambas cuencas.

La reorganización de una red de drenaje señala la movilidad de los cauces fluviales a escala del tiempo geológico. Tal movilidad viene propiciada por la continua tendencia de los cauces fluviales a establecer su perfil en equilibrio, es decir, a alcanzar el trayecto menos energético desde sus cabeceras hasta el nivel de base (Coleman, 1988; Smith et al., 1989; Pastor et al., 2012; Pastor, 2013).

La reorganización fluvial más característica sucede en contextos subsidentes y agradacionales, es decir, en las zonas en que los ríos tienden a depositar sus sedimentos. Al agradar su carga sedimentaria, el cauce de un río puede quedar topográficamente por encima de las zonas colindantes. 
Esta situación genera una inestabilidad debido a que, en una eventual crecida del río, acompañada del desbordamiento del canal, el flujo desconfinado se dirigiría por gravedad hacia las zonas más deprimidas, desde donde probablemente buscaría un nuevo recorrido hacia su nivel de base (Coleman, 1988; Smith et al., 1989). Sin embargo, en contextos geológicos sometidos a un levantamiento del terreno, tal como es el caso de la faja plegada y corrida de la Precordillera, la reorganización es menos común, pues los cauces tienden a incidir en el lecho y a formar valles profundos. Es en estos contextos dominados por la incisión fluvial donde las capturas entre cauces actúan como un mecanismo eficaz de reorganización de la red de drenaje. Las capturas por erosión remontante son las más frecuentes y también las más descritas en la literatura. Lenta o abruptamente, la migración de divisorias y captura de cuencas son parte de los ajustes regionales entre los sistemas de drenaje que resultan de cambios progresivos en respuesta a la actividad neotectónica y al notable contraste en el nivel de base de los dos ríos opuestos a medida que el paisaje evoluciona por erosión fluvial (Sinha-Roy, 2001; Clark et al., 2004; Perucca et al., 2018).

Sea cual sea el mecanismo que propicie la captura, lo cierto es que para que se produzca una captura fluvial es necesaria la intervención de dos cuencas hidrográficas cuyos cauces tengan un distinto potencial erosivo, de modo que pueda generarse una diferencia significativa de cotas entre dos cauces vecinos separados por una divisoria de aguas. Para las cuencas analizadas en este trabajo, se sugiere un futuro proceso de captura en el sector de la cuenca del río Gualilán (que corre de Sur a Norte), debido a la acción remontante del río La Cantera, con mayor potencia de la corriente que el río Gualilán (stream power) (Figura 13a). Por otro lado, la divisoria de aguas de ambas cuencas es un relieve suave, de baja altura y está constituido por afloramientos de areniscas, escasos lentes de conglomerados y limolitas poco compactadas de edad neógena, lo que favorece la erosión (Figura $13 \mathrm{~b}$ y 13c). Como consecuencia de la diferencia de desnivel que tienen que salvar ambos ríos, se producirá la erosión de la divisoria de aguas entre ambas cuencas. De este modo, el río La Cantera capturará al río Gualilán, si bien no es posible determinar el tiempo necesario para que ocurra este proceso de piratería.

En la Figura 13d, se muestra un perfil longitudinal de los ríos Gualilán y La Cantera y su divisoria de aguas. Es posible observar la mayor pendiente del río La Cantera, y el fuerte desnivel respecto del río Gualilán, con menor pendiente y mayor longitud de su cauce principal. En la cuenca del río La Cantera, el desnivel entre el punto más alto de la cabecera en el portezuelo (2182 m) y el río San Juan (1188 m) es de 994 m, mientras que para la cuenca del río Gualilán, el desnivel entre la cabecera $(2182 \mathrm{~m})$ y la desembocadura en la Pampa de Gualilán (1621 m) es de sólo 561 m. El elevado gradiente del cauce principal y el fuerte desnivel entre la cabecera y desembocadura del río La Cantera respecto del río Gualilán, son factores que favorecen directamente la erosión. La erosión retrocedente activa en las cabeceras del río La Cantera orientada hacia la cuenca endorreica del río Gualilán culminaría en un futuro en un proceso de captura de este último y el desvío de sus caudales hacia el captor, con la desembocadura en el nivel de base local (río San Juan). Este proceso es frecuente en los valles tectónicos longitudinales de la Precordillera de San Juan, cuya causa de rejuvenecimiento se considera dinámica (tectónica). La actividad tectónica del SFLC, con al menos cuatro eventos sísmicos durante los últimos 11000 años (Perucca et al., 2015), habría sido un fuerte condicionante en la evolución de estas cuencas.

\section{Conclusiones}

En el presente trabajo se analiza el rol de diversos aspectos geomorfológicos, lineales y areales que influencian la evolución de dos cuencas opuestas ubicadas en un valle intermontano de la faja plegada y corrida de Precordillera, las cuencas de los ríos Gualilán y La Cantera. Los resultados 
derivados de los índices geomorfológicos, morfométricos, morfotectónicos, y perfiles topográficos de franja sugieren un fuerte control tectónico del Sistema de Falla La Cantera, el cual atraviesa longitudinalmente y con rumbo $\mathrm{N}-\mathrm{S}$ todo el valle intermontano y es una fuente sismogénica relevante en el sector. Además, la falla inversa con vergencia al norte ubicada en el mogote La Leona, actúa como divisoria de ambas cuencas, compartimentando el valle longitudinal.

Así, el presente trabajo constituye el primer acercamiento a la identificación y conocimiento de un posible evento de captura en un futuro, debido a la actividad tectónica cuaternaria en esta porción de los Andes Centrales de Argentina. Finalmente, son necesarios estudios de detalle en la depresión para determinar tasas de levantamiento y erosión, además de analizar la problemática de las cuencas vecinas de la margen norte del río San Juan, con el objeto de determinar la influencia de la tectónica y los posibles cambios del nivel de base del principal río que actúa de zona de transferencia hacia el antepaís.

\section{Agradecimientos}

La presente contribución fue financiada con fondos del proyecto PID 0799 del Consejo Nacional de Investigaciones Científicas y Técnicas (CONICET), PID CICITCA 2016-17 (UNSJ) y proyecto GEOF 03 - 2018 del IPGH. Se agradece al CIGEOBIO por proveer los fondos para la licencia del software ArcGIS 10.3. Los autores agradecen, finalmente, a los revisores, Miguel Castillo y María Ortuño Candela, por sus sugerencias y observaciones que contribuyeron a mejorar este trabajo.

\section{Referencias}

Allmendinger, R., Figueroa, D., Zinder, E., Beer, J., Mpodozis, C., Isacks, B.L., 1990, Foreland shortening and crustal balancing in the Andes at $30^{\circ}$ latitude: Tectonics, 9(4), 789-809. https://doi.org/10.1029/tc009i004p00789

Alonso, J.L., Rodríguez-Fernández, L.R., GarcíaSansegundo, J., Heredia, N., Farias, P., Gallastegui, J., 2005, Gondwanic and Andean structure in the Argentine Central Precordillera: The Río San Juan section revisited, en $6^{\circ}$ International Symposium on Andean Geodynamics, París, Francia, IRD Editions (Institut de Recherche pour le Développement), 36-39.

Antón, L., De Vicente, G., Muñoz-Martín, A., Stokes, M., 2014, Using river long profiles and geomorphic indices to evaluate the geomorphological signature of continental scale drainage capture, Duero basin (NW Iberia): Geomorphology, 206, 250-261. https://doi.org/10.1016/j. geomorph.2013.09.028

Bastías, H., 1986, Fallamiento Cuaternario en el área sismotectónica de Precordillera: San Juan, Argentina, Facultad de Ciencias Exactas, Físicas y Naturales, Universidad Nacional de San Juan, tesis doctoral (inédita), $160 \mathrm{p}$.

Bilkra, L.H., Nemec, W., 1998, Postglacial colluvium in western Norway: depositional process, facies and paleoclimatic record: Sedimentology, 45(5), 909-959. https://doi. org/10.1046/j.1365-3091.1998.00200.x

Bishop, P., 1995, Drainage rearrangement by river capture, beheading and diversion: Progress in Physical Geography, 19(4), 449-473. https:// doi.org/10.1177/030913339501900402

Bull, W., 2007, Tectonic Geomorphology of mountains: A new approach to paleoseismology: Oxford, Blackwell publishing, 117-164.

Calvache, M.L., Viseras, C., 1997, LongTerm Control Mechanisms of Stream Piracy Processes in Southeast Spain: Earth Surface Processes and Landforms, 22(2), 93-105. https://doi.org/10.1002/ (sici)1096-9837(199702)22:2<93::aidesp673>3.3.co;2-n 
Clark, M.K., Schoenbohm, L.M., Royden, L.H., Whipple, K.X., Burchfiel, B.C., Zhang X., Tang, W., Wang, E., Chen L., 2004, Surface uplift, tectonics and erosion of eastern Tibet from large-scale drainage pattern:. Tectonics, 23(1), 1-20. https://doi. org/10.1029/2002TC001402

Coleman, J. M., 1988, Dynamic changes and processes in the Mississippi River delta: Geological Society of America Bulletin, 100(7), 999-1015. https://doi. org/10.1130/0016-7606(1988)100<0999:dc apit>2.3.co;2

Finnegan, N.J., Sklar, L., Fuller, T.K., 2007, Interplay of sediment supply, river incision, and channel morphology revealed by the transient evolution of an experimental bedrock channel: Journal of Geophysical Research, 112, F03S11. https://doi. org/10.1029/2006jf000569

Hack, J.T., 1973, Stream-profile analysis and stream-gradient index: U.S. Geological Survey: Journal Research, 4, 421-429.

Horton, R., 1932, Drainage basin characteristics: Transactions, American Geophysical Union, 13 (1), 350-361. https://doi.org/10.1029/ tr013i001p00350

Jordan, T.E., Allmendinger, R.W., Damanti, J.F., Drake, R.E., 1993, Chronology of motion in a complete thrust belt: The Precordillera, 30-31 ${ }^{\circ}$ S, Andes Mountains: Journal of Geology, 101(2), 135-156. https://doi. org/10.1086/648213

Keller, E., Pinter, N., 2002, Active tectonics: Earthquakes, uplift and landscape: New Jersey, Prentice Hall, 362 p.

Mackin, J.H., 1948, Concept of the graded river: Geological Society of America Bulletin, 59 (5), 463-512. https://doi. org/10.1130/0016-7606(1948)59[463:cotgr ]2.0.co;2

Millán, J.L., Perucca, L.P., 2011, Análisis neotectónico del extremo norte del sobrecorrimiento La Cantera, provincia de
San Juan, Argentina: Revista Mexicana de Ciencias Geológicas, 18, 337-348.

Mingorance, F., 1998, Evidencias de Paleoterremotos en la falla activa La CanteraCinturón de empuje de la Precordillera, San Juan, Argentina, en Décimo Congreso Latinoamericano de Geología, Buenos Aires, Argentina: Asociación Geológica Argentina, 161-166.

Molin, P., Pazzaglia, F.J., Dramis, F., 2004, Geomorphic expression of active tectonics in a rapidly-deforming forearc, Sila massif, Calabria, southern Italy: American Journal of Science, 304(7), 559-589. https://doi. org/10.2475/ajs.304.7.559

Moore, I.D., Grayson, R.B., Ladson, A.R., 1991, Digital terrain modelling: a review of hydrological, geomorphological, and biological applications: Hydrological Processes, 5(1), 3-30. https://doi. org/10.1002/hyp.3360050103

NASA, 2011, ASTER Global Digital Elevation Map V2: disponible en <http://gdem. ersdac.jspacesystems.or.jp>.

O'Callaghan, J.F., Mark, D.M., 1984, The extraction of drainage networks from digital elevation data: Computer Vision, Graphics, and Image Processing, 28(3), 323-344. https://doi.org/10.1016/ S0734-189X(84)80011-0

Ortiz, A., Zambrano, J.J., 1981, La provincia geológica Precordillera Oriental, en $8^{\circ}$ Congreso Geológico Argentino, San Luis, Argentina: Asociación Geológica Argentina, 3, 59-74.

Pastor, A., 2013, Las capturas fluviales: contextos, causas y consecuencias. Una explicación de los procesos de captura fluvial en distintos contextos geológicos: Revista de Geografía Espacios, 3(5), 27-41. https://doi. org/10.25074/07 197209.5.347

Pastor, A., Babault, J., Teixell, A., Arboleya, M.L., 2012, Intrinsic stream-capture control of stepped fan pediments in the High 
Atlas piedmont of Ouarzazate (Morocco): Geomorphology, 173-174, 88-103. https:// doi.org/10.1016/j.geomorph.2012.05.032

Perucca, L., Rothis, M., Vargas, H., 2014a, Morphotectonic and neotectonic control on river pattern in the Sierra de la Cantera piedmont, Central Precordillera, province of San Juan, Argentina: Geomorphology, 204, 673-682. https://doi.org/10.1016/j. geomorph.2013.09.014

Perucca, L., Onorato, M., Millán, J., Bustos, A., Vargas, H., 2014b, Variación del estilo de deformación a lo largo del Sistema de falla La Cantera, Precordillera Central, San Juan, Argentina: Revista de la Sociedad Geológica de España, 27(2), 69-79.

Perucca, L., Rothis, M., Bezerra, F., Vargas, H., Lima, J., 2015, Late Quaternary evolution of the La Cantera Fault System (Central Precordillera, Argentina): A morphotectonic and paleoseismic analysis: Tectonophysics, 661, 200-209. https://doi.org/10.1016/j. tecto.2015.08.041.

Perucca, L., Espejo, K., Esper Angillieri, M., Rothis, M., Tejada, F., Vargas, M., 2018, Neotectonic controls and stream piracy on the evolution of a river catchment: a case study in the Agua de la Peña River basin, Western Pampean Ranges, Argentina: Journal of Iberian Geology, 207-224. https://doi. org/10.1007/s41513-018-0052-8.

Phillips, J., Lutz, J., 2008, Profile convexities in bedrock and alluvial streams: Geomorphology, 102, 554-566. https://doi. org/10.1016/j.geomorph.2008.05.042

Poblete, A.G., Minetti, J.L., 1989, Los mesoclimas de San Juan. Primera y Segunda parte. Informe Técnico 11 del Centro de Investigaciones de San Juan: San Juan, U.N.S.J., Boletín 4, 31-32.

Ramos, V.A., 1999, Las provincias geológicas del territorio argentino, en Caminos, R. (ed.), Geología Argentina: Buenos Aires, Instituto de Geología y Recursos Minerales, 29(3), 41-96.
Rolleri, E.O., 1969, Rasgos tectónicos generales del valle de Matagusanos y de la zona entre San Juan y Jocolí: Revista de la Asociación Geológica Argentina, 24, 408-412.

Scheidegger, E., 2004, Morphotectonics: Vienna, Springer, Department of Geodesy and Geophysics, 135 p. https://doi. org/10.1007/978-3-642-18745-2

Scheidegger, E., Ai, N., 1986, Tectonic processes and geomorphological design: Tectonophysics, 126 (2-4), 285-300. https:// doi.org/10.1016/0040-1951(86)90234-9

Schumm, S.A., 1956, Evolution of drainage systems and slopes in bad lands at Perth, Amboi, New Jersey: Geological Society of America Bulletin, 67 (5), 597-646. https://doi. org/10.1130/0016-7606(1956)67 [597:eodsa s] 2.0.co;2

Schumm, S.A., 1977, The fluvial system: New York, Wiley-Interscience, 338 p. https://doi. org/10.2110/pec.81.31.0019

Scotti, V.N., Molin, P., Faccenna, G., Soligo, M., Casas-Sainz, A., 2014, The influence of surface and tectonic processes on landscape evolution of the Iberian Chain (Spain): Quantitative geomorphological analysis: Geomorphology, 206, 37-57. https://doi. org/10.1016/j.geomorph.2013.09.017

Sinha-Roy, A., 2001, Neotectonically controlled catchment capture: An example from the Banas and Chambal drainage basins, Rajasthan: Current Science, 80, 293-298.

Smith, N.D., Cross, T.A., Dufficy, J.P., Clough, S.R., 1989, Anatomy of an avulsion: Sedimentology, 36 (1), 1-23. https://doi. org/10.1111/j.1365-3091.1989.tb00817.x

Snow, S., Slingerland, R., 1987, Mathematical modeling of graded river profiles: Journal of Geology, 95(1), 15-33. https://doi. org/10.1086/629104

Strahler, A.N., 1964, Quantitative geomorphology of drainage basins and channel networks, en Chow, V.T. (ed.), Handbook of Applied Hydrology: New York, McGraw-Hill, 439-476. 
Suriano, J., Limarino, C.O., 2009, Sedimentación pedemontana en las nacientes del Río Jáchal y Pampa de Gualilán, Precordillera de San Juan: Revista de la Asociación Geológica Argentina, 65, 516-532.

Suriano, J., Limarino, G.O., Tedesco, A.M., Alonso, M.S., 2015, Sedimentation model of piggyback basins: Cenozoic examples of San Juan Precordillera, Argentina: GSL Special Publication, 399(1), 221-244. https://doi. org/10.1144/sp399.17

Vargas, M., 2017, Análisis morfométrico y morfotectónico de las cuencas del río La Cantera y del Río Gualilán, Precordillera Central, Provincia de San Juan: tesis de licenciatura de la Universidad Nacional de San Juan (inédita), 85 p.

Villón, M., 2002, Hidrología: Lima, Instituto Tecnológico de Costa Rica, Facultad de Ingeniería Agrícola, Ediciones Villon, 15-64.

Von Gosen, W., 1992, Structural evolution of the Argentine Precordillera: the Río
San Juan section: Journal of Structural Geology, 14(6), 643-667. https://doi. org/10.1016/0191-8141(92)90124-f

Whittaker, A.C., Cowie, P.A., Attal, M., Tucker, G.E., Roberts, G.P., 2007, Bedrock channel adjustment to tectonic forcing: Implications for predicting river incision rates: Geology, 35(2), 103-106. https://doi.org/10.1130/ g23106a.1

Wilson, J.P., Lorang M.S., 1999, Spatial models of soil erosion and GIS, en Fotheringhamand, A.S., Wegener, M. (eds.), Spatial Models and GIS: New Potential and New Models, London, U.K. Taylor and Francis, 83-108.

Zapata, T.R., Allmendinger, R.W., 1996, The thrust front zone of the Precordillera, Argentina: A Thick-skinned triangle zone: American Association of Petroleum Geologists Bulletin, 80, 359-381. https:// doi.org/10.1306/64ed87e6-1724-11d7$8645000102 \mathrm{c} 1865 \mathrm{~d}$ 